\title{
ESTRATIGRAFÍA, PETROGRAFÍA Y ANÁLISIS MULTI-MÉTODO DE PROCEDENCIA DE LA FORMACIÓN GUINEALES, NORTE DE LA CORDILLERA OCCIDENTAL DE COLOMBIA
}

\author{
Gabriel Rodríguez ${ }^{1}$; María Isabel Arango ${ }^{1}$; Gilberto Zapata ${ }^{1}$; José Gilberto Bermúdez ${ }^{1}$
}

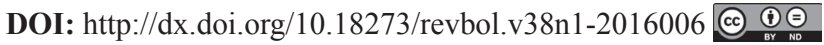

Forma de citar: Rodríguez, G., Arango, M.I., Zapata, G., Bermúdez, J.G. 2016. Estratigrafía, petrografía y análisis multi-método de procedencia de la Formación Guineales, norte de la Cordillera Occidental de Colombia. Boletín de Geología, 38 (1): 101-124.

\section{RESUMEN}

La Formación Guineales se localiza en el norte de la Cordillera Occidental, al oeste del municipio de Dabeiba (Antioquia). Aflora como una franja NNW con $30 \mathrm{~km}$ de largo y tiene un ancho entre 2 y $3 \mathrm{~km}$, formando un monoclinal con disposición $\mathrm{N} 10^{\circ}-23^{\circ} \mathrm{W}$ y buza entre $53^{\circ}-70^{\circ} \mathrm{E}$; está constituida por bancos de conglomerados polimícticos con intercalaciones de capas de areniscas. El análisis estratigráfico estableció un espesor de secuencia de 2.199,26 m en la vía Dabeiba - Mutatá, entre las quebradas Choromandó y Guineales. Las capas de areniscas fueron clasificadas como wacas líticas y litoarenitas; el análisis de procedencia de los cantos determinó varios periodos de deposición de conglomerados con predominio de clastos volcánicos y otros con predominio de clastos sedimentarios. Mediante el análisis multi-método se determina que las unidades de aporte volcánico fueron los Basaltos de El Botón (Mioceno superior), Diabasas de San José de Urama (límite cretácico inferiorjurásico) y el Complejo Santa Cecilia - La Equis (Eoceno inferior) y como aporte sedimentario las Sedimentitas de Las Cruces (Eoceno inferior) y las Litoarenitas, Limolitas y Lodolitas de Urrao (Cretácico superior). La geocronología U-Pb en circones de la matriz arenosa de los conglomerados agrupó intervalos desde el Mioceno (10,5 Ma) hasta el Proterozóico (1.509 a 1.599 Ma), el intervalo más representativo tiene edades del Triásico medio (206,5 a los $287 \mathrm{Ma}$ ), que resultan concordantes con circones metamórficos que provienen del basamento Triásico de la Cordillera Central. El depósito de los conglomerados de la Formación Guineales representa el levantamiento, erosión y acumulación en un ambiente continental donde los ríos corrían de Este a Oeste en la zona de colisión entre el Bloque Cañasgordas y el Bloque Chocó-Panamá y podría estar relacionada con la Orogenia Andina ocurrida en el Plioceno. Basados en las relaciones estratigráficas, análisis de procedencia de clastos y geocronología de los circones detríticos es posible concluir que la acumulación de la Formación Guineales es posterior a 9 Ma (Mioceno tardío).

Palabras clave: Formación Guineales, análisis de procedencia, geocronología U-Pb, Mioceno.

${ }^{1}$ Servicio Geológico Colombiano, grodriguez@sgc.gov.co 


\title{
STRATIGRAPHY, PETROGRAPHY AND PROVENANCE MULTI-METHOD ANALYSIS OF THE GUINEALES FORMATION, NORTHERN OF THE COLOMBIAN WESTERN CORDILLERA
}

\begin{abstract}
The Guineales Formation is located in the northern area of the Cordillera Occidental, to the West of the town of Dabeiba (Antioquia). It crops out as a N-S band, $30 \mathrm{~km}$ long and 2-3 km wide, forming a monocline structure that strikes $\mathrm{N} 10-23^{\circ} \mathrm{W}$ and dips $53-70^{\circ} \mathrm{E}$. It is composed by coarse polimyctic conglomerates with interbedded sandstones. The stratigraphic analysis of the sequence established a total thickness of $2199.26 \mathrm{~m}$ in the Dabeiba - Mutata road between the Choromandó and Guineales creeks. The sandstone layers were classified as lithic wackes and lithic arenites; the provenance analysis of the clasts in the conglomerates showed several cycles of deposition marked by the prevalence of volcanic or sedimentary clasts. The source for the volcanic clast were the Basaltos de El Botón (Upper Miocene), Diabasas de San José de Urama (Jurassic - Lower Cretaceous limit), and Complejo Santa Cecilia - La Equis formations (Lower Eocene), whereas the source for the sedimentary clasts were Sedimentitas de Las Cruces and Litoarenitas, Limolitas y Lodolitas de Urrao formations. The U-Pb geochronology zircons found in the matrix of the conglomerates, shows groups of zircons with ages ranging from Miocene (10.5 Ma) to Proterozoic (1509-1599 Ma), the most representative being the range in age that corresponds to Middle Triassic ( 206.5 to $287 \mathrm{Ma}$ ); this age is consistent with metamorphic zircons that come from the Triassic basement of the Cordillera Central. The depositional event represents uplifting, erosion and accumulation in a continental environment where rivers flowed from east to west in the collision area between the block and Cañasgordas and Chocó- Panama blocks, and could be related to the Andean orogeny occurred in the Pliocene. Based on stratigraphic relationships, provenance analysis of the clasts and detrital zircons geochronology, it is possible to conclude that the accumulation age of Guineales Formation is later than $9 \mathrm{Ma}$ (Upper Miocene).
\end{abstract}

Keywords: Guineales Formation, provenance analysis, U-Pb geochronology, Miocene.

\section{INTRODUCCIÓN}

La Formación Guineales constituye un evento de acumulación de sedimentos erodados a partir del levantamiento de los Andes noroccidentales en Colombia; presenta una pobre descripción en la literatura geológica colombiana, no contaba con una columna estratigráfica y en las descripciones regionales fue mezclada con unidades sedimentarias de diferentes ambientes y edades debido a la complejidad estructural del área donde aflora, fue considerada de edad Eocena por Buchely et al. (2009).

Este trabajo clarifica la información cartográfica, estratigráfica, las relaciones con las unidades circundantes y la edad de acumulación; información necesaria para entender mejor la evolución geotectónica del occidente colombiano. Además, se mejoran aspectos desconocidos, tales como el espesor de la secuencia, contacto inferior, la descripción litológica de los segmentos y se realiza un análisis preliminar multimétodo de procedencia de sedimentos, y también se determinan posibles unidades fuente y edad máxima de acumulación. Se propone la sección tipo a lo largo de la vía Dabeiba - Mutatá, entre las quebradas Choromandó y Guineales, siendo el mejor sitio de exposición y más fácil acceso a la unidad (FIGURA 1).

\section{TRABAJOS ANTERIORES}

Hubach (1930, en De Porta, 1974) describió, en los ríos Tasidó y Tasidocito y en áreas cercanas al municipio de Carepa, una sucesión de arcillolitas y areniscas que reposa discordante sobre los conglomerados del Piso de Nuguiales en la región de Nuguiales-Guineales, sin mayores datos adicionales.

Botero (1936) denomina informalmente con el nombre de Formación Guineales a la unidad de conglomerados que aflora sobre la vía al mar entre la quebrada Guineales al occidente (base de la unidad) y la quebrada Choromandó al oriente (techo de la unidad).

Posteriormente, Muñoz y Zapata (1987) las denominan provisionalmente con el nombre de Rocas Sedimentarias de Beibaviejo-Amparradocito y describen esta unidad como sedimentitas de variada composición y edad; que incluye calizas, conglomerados, areniscas, limolitas y tobas, con edades desde el Eoceno tardío hasta Plioceno temprano, y que descansan discordantemente sobre la Formación Togoridó. 
Mejía y Salazar (1989) la denominan sub-unidad Beibaviejo-Amparradocito; estos mismos autores, en la memoria de la Plancha 114 -publicada en el 2007-, describen el Complejo Riosucio compuesto por dos subunidades litoestratigráficas: la subunidad
Togoridó que incluye las rocas volcánicas efusivas y piroclásticas, las cuales corresponden a los Basaltos de El Botón en el sentido de Zapata y Rodríguez (2012) y la unidad Beibaviejo que corresponde a la Formación Guineales nombrada por Botero (1936).

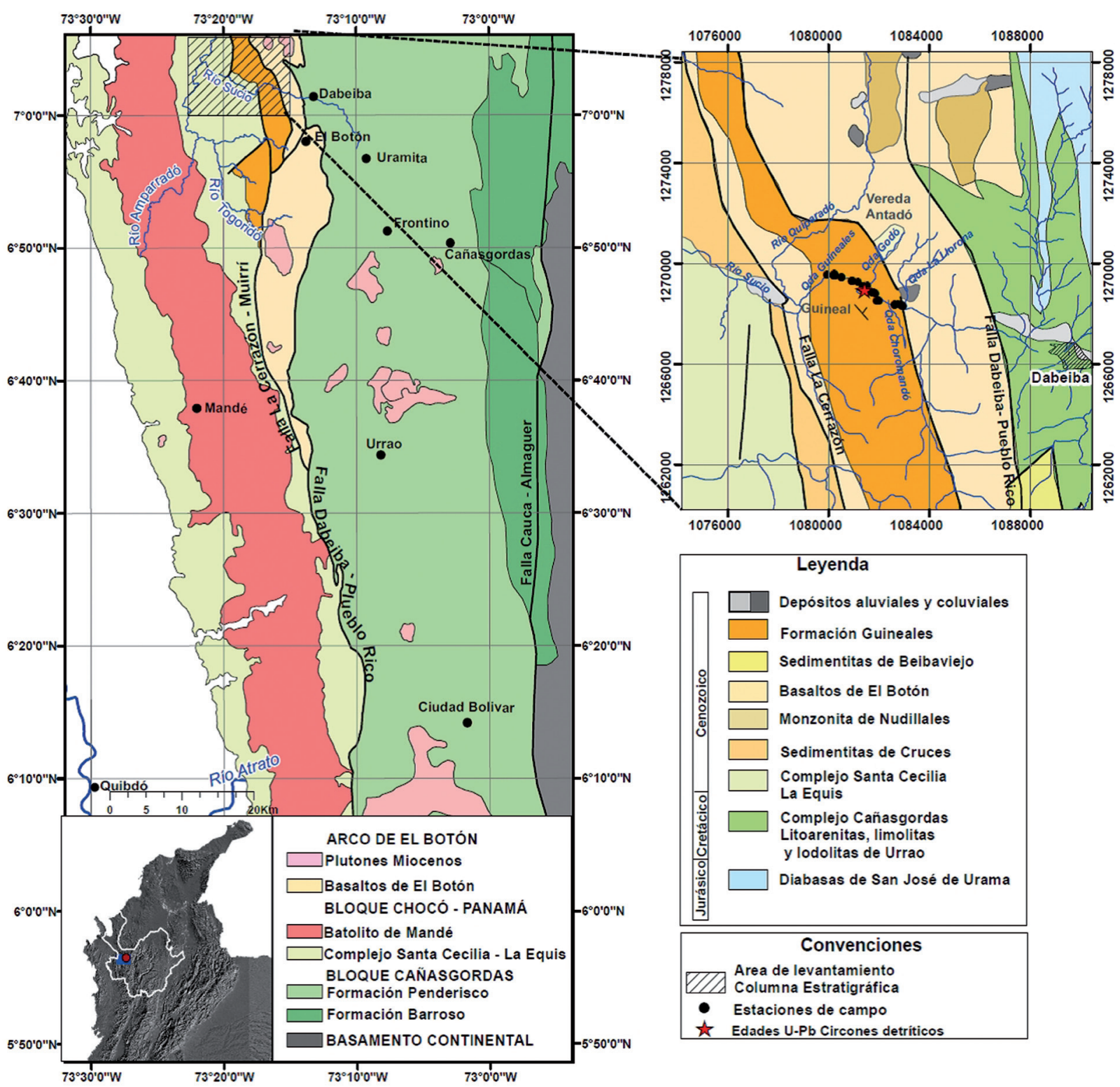

FIGURA 1. Marco regional de la localización de la Formación Guineales y la columna estratigráfica levantada en la carretera Dabeiba - Mutatá.

\section{LOCALIZACIÓN Y MARCO GEOLÓGICO REGIONAL}

La Formación Guineales aflora en el norte de la Cordillera Occidental de Colombia, geológicamente se encuentra en la zona de convergencia del Bloque ChocóPanamá y el Bloque Cañasgordas. El Bloque Chocó-
Panamá está conformado por el Batolito de Mandé (Álvarez, 1971) y el Complejo Santa Cecilia-La Equis (Calle y Salinas, 1986), de edad Eoceno temprano y el Bloque Cañasgordas constituido por un basamento de composición basáltica de afinidad oceánica T-MORB, representado por la unidad Diabasas de San José de Urama (Rodríguez y Arango, 2013; Mejía y Salazar, 
1989) y un conjunto de unidades sedimentarias de edad Cretácico, conocidas en la literatura como Formación Penderisco (Álvarez y González, 1978).

La Formación Guineales se localiza al occidente de la Falla Dabeiba-Pueblo Rico, reposa sobre vulcanitas del Arco de El Botón de edad Mioceno tardío (Basaltos de El Bótón), (FIGURA 1), forma un monoclinal de 30 $\mathrm{km}$ de largo con dirección general NNW y amplitud variable entre 2 y $3 \mathrm{~km}$; se extiende desde el río Togoridó al sur y continua hacia el norte como una franja de aproximadamente $3 \mathrm{~km}$ de ancho.

En el Bloque Cañasgordas, las Diabasas de San José de Urama (Mejía y Salazar, 1989), corresponden a diabasas y basaltos almohadillados (pillow lavas) con texturas ofíticas, subofíticas, intergranulares e intersectales; que afloran como fragmentos tectónicos de afinidad geoquímica con rocas de corteza oceánicas toleítica y basaltos de tipo T-MORB, con una edad probable Jurásico tardío - Cretácico temprano (Rodríguez y Arango, 2013). Las diabasas se encuentran intercaladas y con contactos fallados con bloques de chert - calizas y arcosas - lodolitas, que fueron denominadas por Álvarez y González (1978), como los miembros Urrao y Nutibara de la Formación Penderisco, con edades del Cretácico tardío (a partir del registro fósil). Las rocas anteriores fueron intruidas por dos arcos: al oriente por plutones tonalíticos con contenidos bajos y medios de $\mathrm{K}$ y por cuerpos porfídicos, lavas y tobas de afinidad toleítica a calcoalcalina con edades que corresponden al límite Cretácico temprano - Cretácico tardío (82 a $115 \mathrm{Ma})$, pertenecientes al arco Barroso Sabanalarga (Rodríguez y Arango, 2013); y por el Arco volcánico - plutónico de "El Botón", constituido por lavas de composición andesítico basálticas con texturas porfiríticas, tobas y plutones monzodioríticos - monzoníticos, de afinidad shoshonítica y de edad Mioceno tardío (9 a $12 \mathrm{Ma}$ ) (Zapata y Rodríguez, 2012 y Rodríguez y Zapata, 2012).

Al occidente de la Formación Guineales, afloran las Sedimentitas de Cruces que reposan sobre el arco volcano plutónico de Chocó - Panamá. Las Sedimentitas de Cruces están constituidas por calizas, lodolitas calcáreas, calizas arenosas, limolitas, areniscas y areniscas conglomeráticas con aporte volcánico, y presentan fauna fósil del Eoceno (Rodríguez et al., 2014). El arco Chocó- Panamá lo constituye una unidad volcánica denominada Complejo Santa Cecilia - La Equis y un plutón en el núcleo que se ha llamado Batolito de Mandé; las rocas volcánicas del arco corresponden a basaltos y andesitas basálticas porfídicas y tobas; la parte plutónica corresponde al Batolito de Mandé de composición predominante tonalítica. La afinidad química del arco es calcoalcalina con contenido medio de $\mathrm{K}$ y edad Eoceno temprano (43 a $48 \mathrm{Ma}$ ) (Rodríguez et al., 2014).

En resumen, la parte norte de la Cordillera Occidental está constituida por tres arcos compuestos de vulcanitas y plutonitas de edades Mioceno tardío, Eoceno temprano y limite Cretácico tardío - Cretácico temprano, además de una unidad de corteza oceánica constituida por diabasas y basaltos almohadillados de afinidad toleítica con intercalaciones tectónicas de sedimentitas (chert, calizas, litoarenitas y lodolitas).

\section{METODOLOGÍA}

Se realizó el levantamiento continuo de la columna estratigráfica a lo largo de la vía que une los municipios de Dabeiba y Mutatá, en ocasiones la descripción se siguió a lo largo de los drenajes que cortan la vía debido a la existencia de puentes sin afloramientos. Se utilizó el método de poligonal abierta para determinar los espesores de la secuencia, midiendo el rumbo y buzamiento de las capas y posteriormente se hizo la corrección de espesores.

En las capas de conglomerados se realizó un muestreo aleatorio de las partículas que tienen tamaños desde 2 a $30 \mathrm{~cm}$ y que conforman el armazón; se tomaron 20 clastos por capa para su identificación macroscópica (naturaleza litológica) calculando el porcentaje de cada litología, para ser clasificados en los triángulos de Folk (1954) para descripción textural y Folk (1974) para la clasificación composicional. El predominio litológico en los paquetes de conglomerados permitió dividir la secuencia en segmentos.

Las muestras se recolectaron cada $100 \mathrm{~m}$ en la sucesión sedimentaria, se tomó un clasto de cada litología teniendo en cuenta los menos alterados o meteorizados, permitiendo identificar los diferentes tipos litológicos y su contenido en las capas conglomeráticas. Así fue posible observar la litología que representan los segmentos en que fue dividida la unidad. En total se escogieron 32 muestras para la elaboración de sección delgada y análisis petrográfico.

De las 32 muestras se determinaron las características texturales y composicionales de las rocas al microscopio de luz polarizada. La clasificación de rocas volcánicas se hizo según Streckeisen (1979), las areniscas según Folk (1974) y las calizas de acuerdo a Folk (1962), mediante conteo de 300 puntos; los resultados se graficaron en los respectivos triángulos. 
Con la información anterior se realizó una comparación con unidades aflorantes en la Cordillera Occidental, teniendo en cuenta los resultados publicados por Rodríguez et al. (2010, 2014), Zapata y Rodríguez (2012), Buchely et al. (2009) y Rodríguez y Arango (2013).

De los segmentos con predominio de vulcanitas, se escogieron en total diez (10) clastos de rocas volcánicas bajo el criterio que no estuvieran meteorizados o alterados, se les hizo análisis químico para óxidos mayores en los laboratorios del Servicio Geológico Colombiano por el método de Absorción Atómica. El laboratorio tiene establecida la siguiente metodología:

- La muestra es triturada, homogenizada y pulverizada a malla -100

- Se pesa 0,1000 gr de muestra seca a $105{ }^{\circ} \mathrm{C}$ en un recipiente plástico

- Se agregan $4 \mathrm{ml}$ de HF (ácido fluorhídrico) al 40\%, se tapa y se deja reposar durante una noche.

- Se agregan 1,5 ml de $\mathrm{HCl}$ (ácido clorhídrico) concentrado y $0,5 \mathrm{ml}$ de $\mathrm{HNO}_{3}$ (ácido nítrico) concentrado, se tapa el recipiente plástico y se calienta al "baño maría" durante 1 hora a $80^{\circ} \mathrm{C}$.

- Se bajan los recipientes del baño maría y se agregan $50 \mathrm{ml}$ de solución de ácido bórico al 5\% que contiene 2.000ppm de $\mathrm{Cs}(\mathrm{Cesio})$

- Se dejan los recipientes en reposo y se agitan cada 15 min durante 1 hora.

- Se lleva a Volumen de $100 \mathrm{ml} \mathrm{y}$ se leen por Absorción Atómica los diferentes elementos.

Los resultados químicos obtenidos en clastos volcánicos de la Formación Guineales fueron comparados con la litogeoquímica de unidades de origen volcánico que afloran en el norte de la Cordillera Occidental de Colombia, mediante la definición de los campos en el diagrama TAS- (Le Bas et al., 1986) y en el diagrama $\mathrm{K}_{2} \mathrm{O}$ vs $\mathrm{SiO}_{2}$ (Peccerillo and Taylor, 1976); estos campos fueron delimitados con base en la distribución de los resultados químicos publicados para muestras del Arco de El Botón (Zapata y Rodríguez, 2012; Rodríguez y Zapata, 2013), del Complejo Santa Cecilia-La Equis (Buchely et al., 2009; Rodríguez et al., 2010; Rodríguez et al., 2014) y para muestras de la Formación Barroso y las Diabasas de San José de Urama (Rodríguez y Arango, 2013).
En el segmentos 6 debido a los abundantes clastos de vulcanitas, se identificaron probables fuentes de aporte volcánico. Se realizó concentración de minerales pesados mediante batea (cinco concentrados) de la matriz arenosa en diferentes capas de conglomerados. La separación física y montaje de los circones detríticos se realizó en los laboratorios del Servicio Geológico Colombiano, separando del concentrado de minerales pesados la no magnética, la cual por medio de la lupa binocular se logró identificar únicamente 40 circones detríticos, que fueron enviados al Laboratorio de Estudios Isotópicos (LEI) del Centro de Geociencias de la Universidad Nacional Autónoma de México (UNAM).

La metodología de datación de circones fue descrita por el laboratorio de la UNAM (CGEO) en el informe de resultados que incluye esta muestra, la cual se resume a continuación:

En los laboratorios del CGEO, los granos de circón fueron seleccionados cuidadosamente bajo un microscopio binocular, siendo montados en una cinta y posteriormente llevados a una probeta (un anillo plástico de 2,5 $\mathrm{cm}$ de diámetro) que se rellena de resina epóxica (Struers Epofix), dejándose endurecer. El cilindro obtenido se desbasta por medio de papel lija (\# 800, 1.500, y 3.000) hasta exponer una superficie lo más cercana posible a la mitad ecuatorial de los circones. Antes de los análisis in situ por ablación láser, las superficies pulidas de los granos de circón fueron fotografiadas en catodoluminiscencia $(\mathrm{CL})$ por medio del empleo de un luminoscopio ELM-3R (Marshall, 1988). Las imágenes de CL y luz reflejada fueron obtenidas con el propósito de caracterizar la estructura interna de los circones y elegir los sitios potenciales para los análisis de $\mathrm{U}-\mathrm{Pb}$, observando el zonamiento relacionado a los cambios de composición química de los circones, para poder detectar posibles inclusiones, sobrecrecimientos metamórficos o herencias que cambiarían el sentido de la interpretación de los datos analíticos.

Una vez realizada la CL se procede a seleccionar los puntos más idóneos para el fechamiento, observando las imágenes de CL y la homogeneidad de los granos, teniendo en cuenta el tamaño del punto analítico que se empleará (en el caso del presente trabajo, $23 \mu \mathrm{m}$ ). En las secuencias analíticas se intercalan un estándar de vidrio (NIST 610), y dos estándares naturales de circón; uno primario (91500, Wiedenbeck et al., 1995) y uno secundario Plésovice (Slama et al., 2008) que sirve como control de calidad. 
Los análisis isotópicos de U-Pb y concentraciones de los elementos traza (REE) en circones se obtuvieron por la técnica de ablación láser (LA-ICPMS) mediante la medición de estándares certificados (circones estándar 91500 y vidrio NIST SRM 610) cada cinco (5) mediciones en los circones de interés, con el fin de realizar corrección de masa y deriva instrumental. El control de lecturas en los circones 91500 son usados para recalcular las relaciones isotópicas mientras que el vidrio NIST se utiliza para calcular las concentraciones de $\mathrm{U}, \mathrm{Th}$, elementos traza y tierras raras.

El LEI cuenta con un sistema de ablación láser modelo Resolution M50 de la marca "Resonetics" compuesto por un láser LPX 220 tipo excímero de $193 \mathrm{~nm}$ de longitud de onda, que utiliza una mezcla de fluoruro de argón (ArF) para generar la pulsación. Este se encuentra acoplado a un espectrómetro de masas (ICP-MS) tipo cuadrupolo marca "Thermo X-Series". El sistema fue recientemente descrito por (Solari et al., 2010), quienes presentaron la metodología para los análisis isotópicos $\mathrm{U}(\mathrm{Th})-\mathrm{Pb}$ en circones.

Previo a la medición isotópica, las muestras (probeta con circones) se limpiaron con HNO3 1M con la finalidad de eliminar o minimizar cualquier posible contaminación por la presencia de $\mathrm{Pb}$ común en la superficie de los granos. $\mathrm{La}$ ablación láser se realiza en una celda de nueva generación de doble volumen que puede alojar hasta cuatro probetas, una de las cuales tiene montados los estándares a utilizarse, y las otras tres las muestras. Los cristales de circón fueron ablacionados dentro de esta celda en una atmósfera de $\mathrm{He}$, la cual proporciona una condición óptima para este proceso (Eggins et al., 1998; Kosler and Sylvester, 2003). El haz del láser incide sobre la superficie del cristal en el punto previamente seleccionado, con una densidad de energía de $\sim 6 \mathrm{~J} / \mathrm{cm} 2$ y a una tasa de repetición de $5 \mathrm{~Hz}$ creando un hoyo provocado por la volatilización de un área del circón (punto de análisis) de $23 \mu \mathrm{m}$ de diámetro y de $\sim 15 \mu \mathrm{m}$ de profundidad para obtener un total de $\sim 75-85$ ng de masa ablacionada durante cada análisis. La ablación se lleva a cabo por $30 \mathrm{seg}$ con el fin de minimizar la profundidad del hoyo de ablación y el fraccionamiento elemental. Posteriormente, el material ablacionado (vaporizado) es sacado de la celda de ablación y transportado al espectrómetro de masas en un flujo de $\mathrm{He}(700 \mathrm{ml} / \mathrm{min})$ que se mezcla con N2 (ca. $3 \mathrm{ml} / \mathrm{min}$ ) y con Ar para ser analizado.

\section{DESCRIPCIÓN GEOLÓGICA}

La Formación Guineales presenta una disposición estructural $\mathrm{N} 10$ a $23^{\circ} \mathrm{W}$ buzando entre 53 a $70^{\circ} \mathrm{E}$, forma un monoclinal con un espesor total de secuencia levantada de 2.199,26 m (FIGURA 2). La unidad ha sido dividida en nueve segmentos de acuerdo al predominio litológico de los clastos que conforman los conglomerados. Está constituida por bancos gruesos de conglomerados clasto soportados, polimícticos, con regular a mala selección que están levemente imbricados. La composición de los clastos es de chert, areniscas, vulcanitas, calizas y esporádicas plutonitas de composición dioritoide, con escazas intercalaciones de areniscas conglomeráticas de composición litoarenitas en capas gruesas.

El levantamiento de la columna se realizó con un punto de inicio N:1'269.542 m, E:1'079.920 m y un punto final N:1'268.325 m y E:1'082.968 m en origen Magna Oeste. Desde la base de la columna hasta la parte superior del segmento 3, se aprecia una gradación inversa en la sucesión iniciando con conglomerados arenosos a conglomerados clasto soportados.

\section{Segmento 1}

Representa la base de la columna, el espesor del segmento es de 263,56 m de los cuales $134,5 \mathrm{~m}$ son cubiertos. Está compuesto por paquetes espesos de conglomerados arenosos de color gris a marrón y areniscas conglomeráticas de color marrón en contactos ondulosos. Los conglomerados están constituidos por guijarros de tamaños entre 2 y $5 \mathrm{~cm}$, subangulosos a subredondeados de baja esfericidad de chert negro (entre 60 a 100\%), sublitoarenitas (20\%), vulcanitas $(10 \%)$, y en menor cantidad clastos de lodolitas. La proporción clastos - matriz en los conglomerados desde la base hacia el techo del segmento varía con empaquetamientos flotantes en una matriz de arenisca de grano grueso a conglomerática de composición litoarenita, constituida por líticos sedimentarios, chert, cuarzo y moscovita, hasta empaquetamientos puntuales a completos de guijarros.

En la parte superior se presenta una capa gruesa de $10 \mathrm{~m}$ de arenisca color marrón de grano muy grueso a grava, de composición chertarenita con el $100 \%$ de clastos de chert.

\section{Segmento 2}

Muestra un espesor de 295,07 $\mathrm{m}$ donde solo se exponen $37 \mathrm{~m}$ de afloramiento; este segmento se caracteriza por una intercalación entre dos capas gruesas de conglomerados con una capa gruesa de arenisca. Las capas de conglomerado varían en espesor entre 12 a 18 $\mathrm{m}$, en general son clasto soportados con pobre selección y están constituidos por guijarros de tamaño entre 2 y 6 $\mathrm{cm}$. La composición de las partículas en la capa inferior 
del segmento es de chert (80\%), litoarenitas de grano fino $(20 \%)$ y en menor proporción vulcanitas $(<5 \%)$, en las capas superiores de este segmento se observa un cambio en el predominio de la composición de los clastos, pasando a contenidos de chert (40\%) y mayor presencia de clastos de litoarenitas $(70 \%)$. La matriz en las capa de los conglomerados puede alcanzar hasta el $20 \%$, y está compuesta por una arenisca de tamaño de grano medio de composición litoarenita. La capa gruesa de arenisca tiene un espesor de $8 \mathrm{~m}$; es de color marrón y está compuesta por granos de tamaños medio con esporádicos gránulos de tamaño guijo de chert $(60 \%)$, cuarzo $(25 \%)$, plagioclasa $(10 \%)$ y moscovita $(<2 \%)$. Los contactos entre granos son puntuales a completos, presenta un contenido de matriz lodosa menor al $5 \%$.

\section{Segmento 3}

Tiene un espesor de 286,03; se distingue por el predominio de intercalaciones de conglomerados clastos soportados con contactos erosivos dispuestos en capas muy gruesas (de 10 a $50 \mathrm{~m}$ ) que se alternan con areniscas en capas muy gruesas de 10 a $15 \mathrm{~m}$, ondulosas no paralelas (FIGURA 3C). Las areniscas son de composición sublitoarenita con tamaños de grano grueso a conglomeráticas, están compuestas por líticos sedimentarios (85\%), cuarzo (10\%), y una matriz lodosa $(5 \%)$. En la parte media del segmento las areniscas son de grano fino a medio y contienen restos de tallos, fragmentos de turba e impresiones de hojas (FIGURA 3E, F). Los conglomerados gradan de base a techo de matriz soportados a clasto soportados. Los clastos tienen tamaños desde 1 a $12 \mathrm{~cm}$ y están compuestos por litoarenitas y cuarzoarenitas $(80 \%)$, chert $(15 \%)$ y volcanoclastos (5\%). En el interior de las capas de conglomerados se presentan lentes arenosos de formas irregulares, masivos de composición litoarenita.

\section{Segmento 4}

Este segmento tiene un espesor de 196,54 m. Hacia su base está constituido por conglomerados con predominio de clastos de vulcanitas, los cuales estaban ausentes o en bajas cantidades en los segmentos 1,2 y 3 de la columna y pasan a ser dominantes con el $80 \%$; el $20 \%$ restante lo conforman guijos y guijarros de sedimentitas arenosas. El contenido de matriz en los conglomerados es menor del $25 \%$ y está compuesta por una litoarenita de color marrón claro de tamaño arena media a muy gruesa, con mala selección. En la parte superior de este segmento el predominio de los clastos varía entre vulcanitas $(30 \%)$ y calizas micríticas de color gris $(60 \%)$, subordinado por clastos de litoarenitas $(10 \%)$.

\section{Segmento 5}

Fue levantado en la quebrada Godó, con un espesor de 16,20 m (FIGURA 1). Su base está constituida por una capa gruesa de conglomerado clasto soportado que grada a matriz soportado con tamaños de cantos entre 5 y $15 \mathrm{~cm}$, de composición chert (65\%), areniscas (30\%) y vulcanitas $(5 \%)$. Hacia la parte superior del segmento se observa una gradación normal de los conglomerados hacia areniscas de composición litoarenitas de grano grueso.

\section{Segmento 6}

Tiene un espesor de 251,51 m. En este segmento predominan las capas gruesas de 10 y $25 \mathrm{~m}$ de conglomerados. Hay mayor cantidad de clastos de composición volcánica (basaltos porfídicos y basaltos piroxénicos) hasta en un $60 \%$ de tamaños de canto mayores a $10 \mathrm{~cm}$. Son frecuentes los lentes arenosos irregulares masivos de tamaño métrico. En la parte superior del segmento 6 hay un cambio transicional en el tipo de clastos que predomina, pasando de cantos volcánicos a cantos de litoarenitas.

\section{Segmento 7}

$\mathrm{Su}$ espesor es de 203,43 m. En este segmento se diferencian dos intervalos; el primero de ellos se describe hacia la base como una alternancia de capas gruesas de $10 \mathrm{~m}$ de conglomerados clasto soportados con predominio composicional de areniscas de tamaño guijarro entre 5 y $10 \mathrm{~cm}$, con capas de lodolitas que tiene espesores de 5 a $13 \mathrm{~m}$. Las lodolitas son de color gris oscuro, ligeramente conglomeráticas con guijos angulares de chert negro de $1 \mathrm{~cm}$ de diámetro y fragmentos centimétricos de turba. El intervalo superior comprende la parte media a superior del segmento, donde hay un predominio de capas muy gruesas hasta de $40 \mathrm{~m}$ de espesor de conglomerados clasto soportados con contactos ondulosos. El predominio en la composición de los clastos varía de areniscas a calizas micríticas con tamaños guijarro a canto 5 a $10 \mathrm{~cm}$ de colores gris a marrones y en menor cantidad rojizas.

\section{Segmento 8}

Presenta un espesor de 435,89 m; este segmento se caracteriza por sus capas más gruesas de conglomerados de hasta $60 \mathrm{~m}$ de espesor con contactos entre capas ondulosos a transicionales. Está constituido por conglomerados clasto soportados con empaquetamientos completos a puntuales. Los clastos se encuentran dispuestos de manera errática con partículas que alcanzan tamaños desde cantos hasta bloques $(30 \mathrm{~cm})$, subangulares a subredondeados, de calizas micríticas 
(60\%), vulcanitas $(20 \%)$, areniscas $(15 \%)$ y chert (5\%). La matriz está compuesta por arenisca gruesa a conglomerática de composición litoarenita. Hacia la parte media del segmento se observa una intercalación de capas de conglomerados que gradan a capas de litoarenitas de tamaño arena gruesa, además hacia la parte superior el predominio de partícula en los conglomerados varía de calizas a vulcanitas.

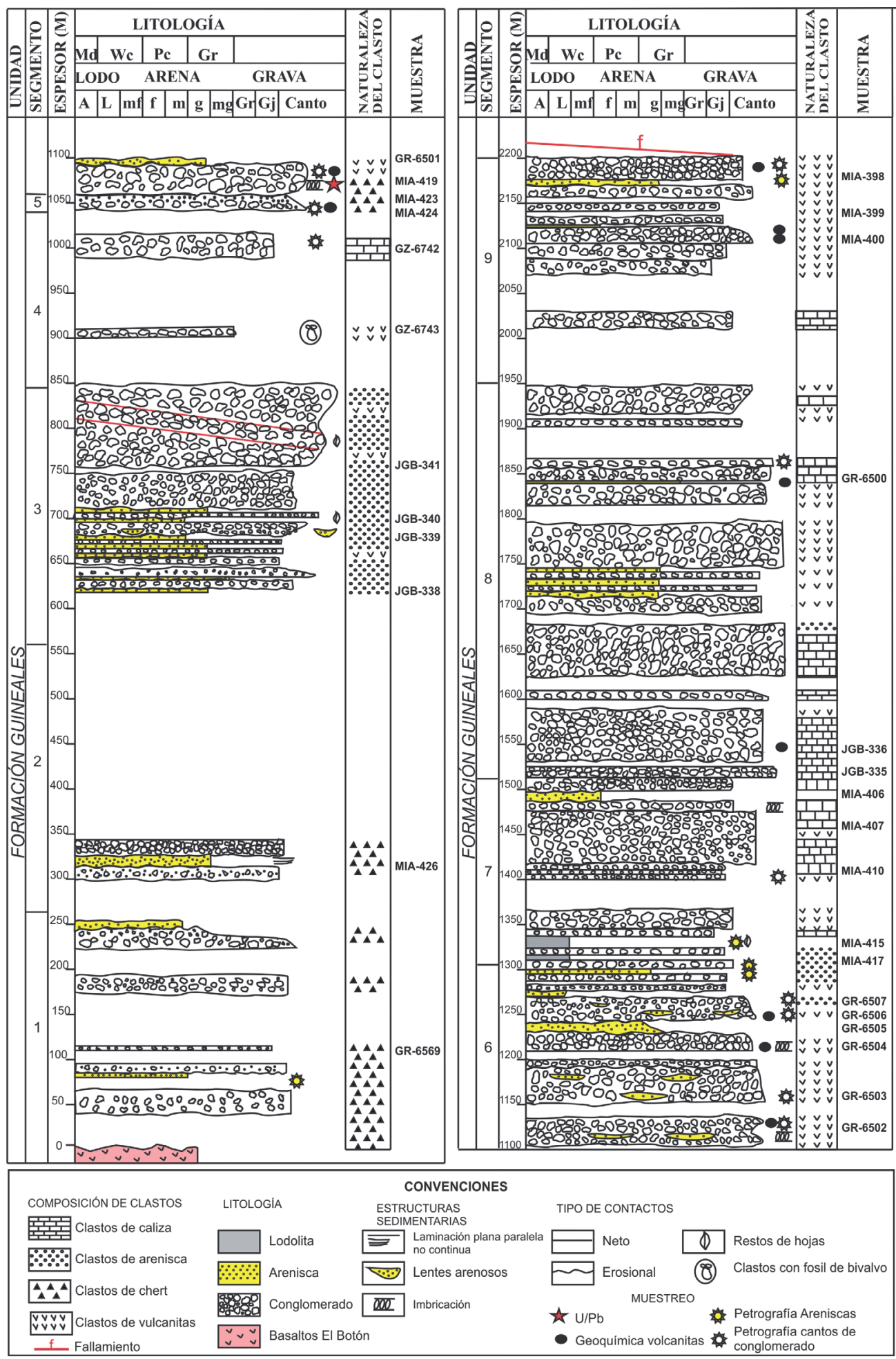

FIGURA 2. Columna estratigráfica de la Formación Guineales levantada en la vía Dabeiba - Mutatá (sección tipo). 

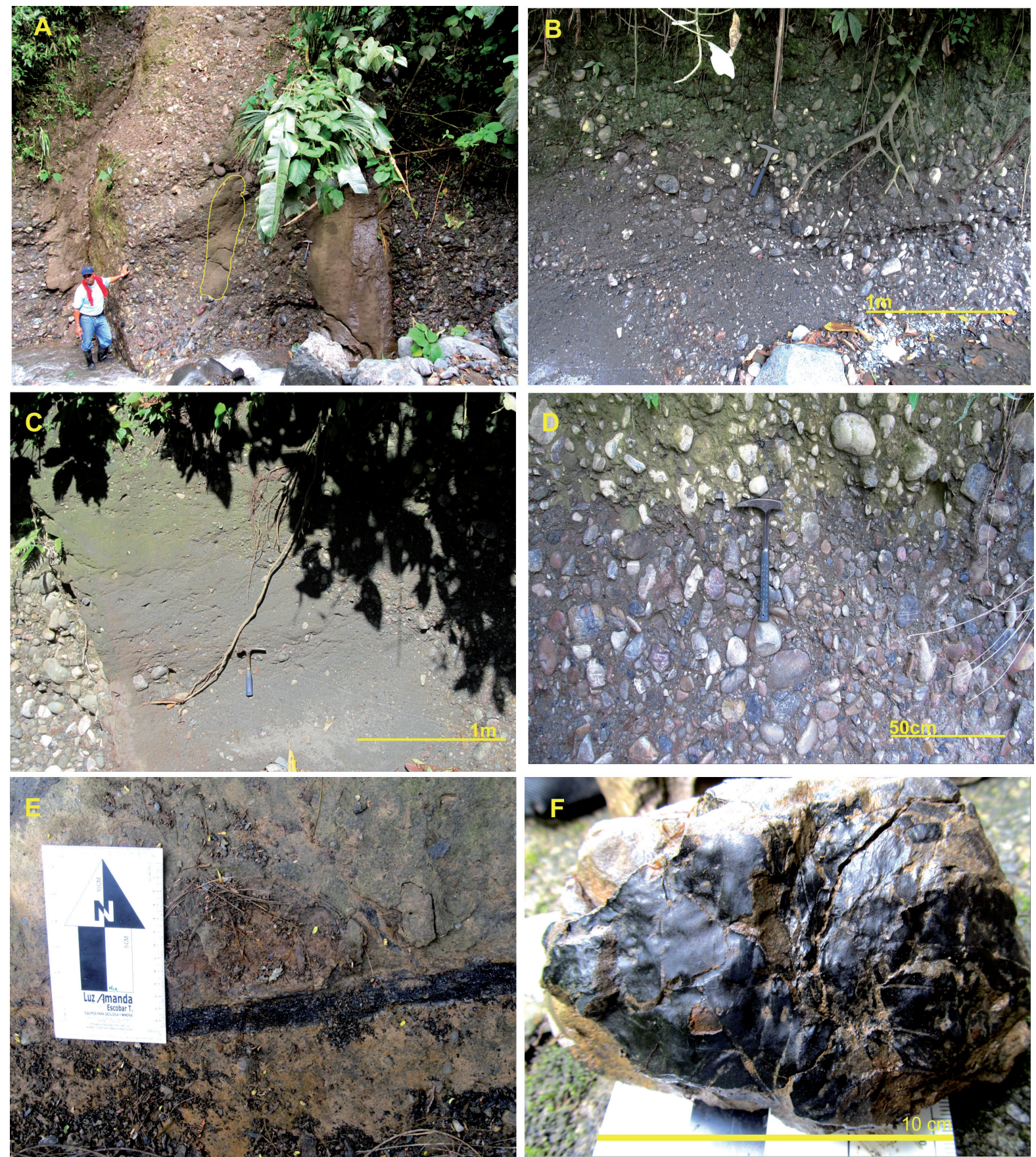

FIGURA 3. Aspectos sedimentológicos a escala macroscópica de la Formación Guineales. A. Intercalaciones de capas de areniscas con capas de conglomerados que contienen lentes arenosos (en amarillo) (segmento 6 Quebrada Godó). B. Contacto gradacional normal de areniscas a conglomerados. Quebrada Godó (segmento 5). C. Contacto neto entre capas de arenita y conglomerado (segmento 3, estación JGB-340). D. Aspecto general de los conglomerados polimícticos matriz-soportados con pobre selección. E. Lodolitas grises con guijos de chert y fragmentos de turba (segmento 3, JGB-340). F. Acumulación de restos de hojas carbonizadas en capas de sublitoarenitas. (segmento 3, JGB-341).

\section{Segmento 9}

Este último intervalo tiene un espesor de $251,03 \mathrm{~m}$. Comienza a partir de un cubierto de $65 \mathrm{~m}$, predominan las capas gruesas de 15 a $20 \mathrm{~m}$ de conglomerados clasto soportados con contactos entre las capas ondulosos. Los clastos tienen tamaños guijarros a cantos, son subangulares a subredondeados y corresponden predominantemente a basaltos porfídicos $(75 \%)$ compuestos por fenocristales de piroxenos y plagioclasa y una matriz afanítica de 
color verde a gris. Clastos de calizas $(20 \%)$ en guijarros subredondeados y chert $(5 \%)$. El segmento presenta intercalaciones menores de capas gruesas de $5 \mathrm{~m}$ de areniscas color marrón, de composición litoarenita con abundancia de líticos volcánicos.

\section{Descripción microscópica}

La descripción microscópica de la Formación Guineales se restringe a cinco (5) muestras petrográficas de las capas de areniscas y lodolitas que se intercalan con las capas de conglomerados que predominan en la unidad. En la TABLA 1 se resumen los resultados de los análisis petrográficos y en la FIGURA 2 se muestra su ubicación en la columna estratigráfica.

Las muestras se clasifican como wacas líticas y litoarenitas con predominio de granos líticos de chert y subordinados granos de vulcanitas y lodolitas.

TABLA 1. Clasificación petrográfica de areniscas de la Formación Guineales.

\begin{tabular}{|c|c|c|c|c|c|c|c|c|c|c|c|c|c|c|}
\hline IGM & Qtz & Pl & Kfs & Cpx & Hbl & Bt & Op & Zrn & Ep & MATRIZ & CEMENTO & FR & OTROS & $\begin{array}{l}\text { CLASIFICACIÓN } \\
\text { PETROGRÁFICA }\end{array}$ \\
\hline 900611 & 32 & 2 & & 2,5 & & 1 & TR & 0,5 & 1,5 & 17 & 2 & 41 & & WACA LÍTICA \\
\hline 900612 & 44,5 & 1,5 & 2,5 & & $\mathrm{TR}$ & & & & 5 & 19,5 & $\mathrm{TR}$ & 27,5 & $\mathrm{tr}$ & $\begin{array}{l}\text { WACA LÍTICA RICA EN } \\
\text { CHERT }\end{array}$ \\
\hline 900613 & 34 & 1,5 & & & 1,5 & & & & 3 & 18 & TR & 42 & & LITOARENITA \\
\hline 900614 & 49 & 2,5 & & & 5,5 & TR & & & 6,5 & 10 & TR & 25,5 & 1 & $\begin{array}{l}\text { LITOARENITA RICA EN } \\
\text { CHERT }\end{array}$ \\
\hline 900622 & 4,6 & & & & & & TR & & & & 13,7 & 81,7 & & CHERT ARENITA \\
\hline
\end{tabular}

Los granos de chert son generalmente angulares de tamaño entre limo y guijo fino de color rojizo a marrón, constituidos por sílice microcristalina a criptocristalina, algunos de ellos con presencia de esferulitos rellenos de calcedonia con textura fibrosa radial y bioclastos de foraminíferos de tamaño 0,1 a 0,2mm, de forma globosa con su molde interno relleno de opacos o calcedonia y los bordes reemplazados por esparita. Los líticos volcánicos corresponden a fragmentos angulares de andesitas con textura microlítica hialocristalina constituidas por una matriz vítrea de color pardo a gris, con microlitos euhedrales de plagioclasa. Son frecuentes y abundantes los granos de cuarzo de tamaño limo a arena muy gruesa, generalmente en cantidades entre $32 \%$ y $49 \%$, monocristalinos, en menor proporción $(<3 \%)$ se presenta plagioclasa y escasos feldespatos alcalinos, piroxeno, hornblenda, biotita y opacos que pueden o no estar presentes.

En algunas wacas y litoarenitas (MIA-398-4 y MIA415-52) se presentan líticos de lodolitas en granos de color marrón con tamaño entre 0,3 a $1 \mathrm{~mm}$, subangulares y ocasionalmente granos líticos de arcillolitas y cuarzoarenitas. La matriz de las wacas líticas y de algunas litoarenitas (FIGURA 4) corresponde a material lodoso o arcilloso, de color pardo y finas láminas de sericita de tamaño limo, se presenta rodeando los terrígenos. La muestra GR-6569 que corresponde a una chert arenisca ligeramente conglomerática presenta cemento calcáreo que rellena los espacios intersticiales entre los granos de chert (FIGURA 4B).
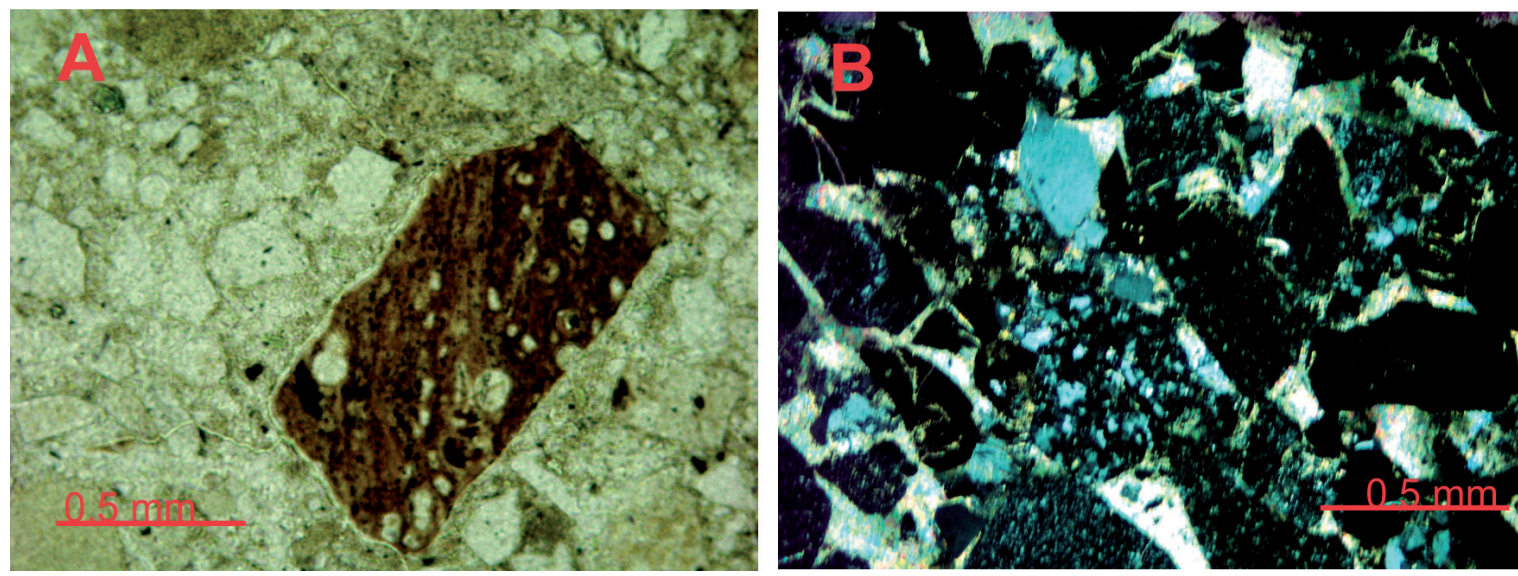

FIGURA 4. A. MIA-417-52C. Litoarenita. Lítico subangular de chert con oolitos de calcedonia, cuarzo, envuelto en una matriz arcillosa de color marrón. B. GR-6569. Chert arenita. Roca clástica compuesta por fragmentos líticos de tamaño arena a guijo fino, principalmente de chert y subordinados litoarenitas, con cemento intergranular cálcico. 


\section{ANÁLISIS DE PROCEDENCIA}

Para definir probables unidades de aporte de los conglomerados de la Formación Guineales se realizó un trabajo de análisis de procedencia multi-método, teniendo en cuenta la gran variedad litológica de los clastos, las probables unidades de aporte y las limitaciones de cada método para determinar unidades fuentes de diferente litología y ambiente. Este estudio combina la geoquímica de clastos volcánicos y su comparación con los campos geoquímicos de unidades volcánicas que afloran en el norte de la Cordillera Occidental de Colombia, además, complementa estos resultados con análisis petrográficos de clastos de vulcanitas, calizas y areniscas. Así mismo, compara el registro fósil de las calizas y la composición de las areniscas con las de unidades sedimentarias que afloran en el norte de la Cordillera Occidental. Por último, se hizo muestreo y análisis preliminar de procedencia de circones en un segmento de la columna.

\section{Procedencia de clastos de vulcanitas}

En el sector norte de la Cordillera Occidental afloran cuatro unidades de vulcanitas que pudieron aportar sedimentos detríticos a la unidad, las cuales tienen características litogeoquímicas particulares que permiten por comparación de los resultados obtenidos en algunos clastos, determinar de manera indirecta y preliminar (debido al limitado número de muestras analizadas), algunas unidades fuente. La firma geoquímica de las unidades volcánicas ha sido descrita recientemente por Zapata y Rodríguez (2012), Rodríguez y Zapata (2012), Rodríguez et al. (2010), Buchely et al. (2009) y Rodríguez y Arango (2013), para las Diabasas de San
José de Urama, las vulcanitas de arco de la Formación Barroso, el Complejo Santa Cecilia - La Equis y los Basaltos y plutones del Arco de El Botón.

Las Diabasas de San José de Urama corresponden a basaltos de la serie toleítica, con bajo contenido de $\mathrm{K}$ y afines con un ambiente T-MORB, generadas posiblemente en un Plateau oceánico con una edad probable en el limite Jurásico - Cretácico temprano (?) (Rodríguez y Arango, 2013). El Complejo Santa Cecilia - La Equis está constituido por lavas basálticas y andesíticas, rocas piroclásticas de la serie calcoalcalina, con contenido medio de $\mathrm{K}$ y subordinadas algunas rocas de la serie toleítica de edad Eoceno temprano, generadas en un arco (Buchely et al., 2009; Rodríguez et al., 2010); las vulcanitas de la Formación Barroso corresponden a rocas subalcalinas de la serie toleítica y la serie calcoalcalina bajas en contenido de $\mathrm{K}$, generadas en un arco durante el limite Cretácico inferior - Cretácico superior (Rodríguez y Arango, 2013) y por último se presenta el Basalto de El Botón que corresponde a series shoshoníticas enriquecidas en $\mathrm{K}$ de edad Mioceno medio - Mioceno tardío (9 a $12 \mathrm{Ma}$ ), que según Zapata y Rodríguez (2012), se generaron en un arco de margen continental. En la TABLA 2 se muestran los resultados geoquímicos de los clastos volcánicos de la Formación Guineales.

Las FIGURAS 5A y B (diagrama TAS y diagrama de $\mathrm{K}_{2} \mathrm{O}-\mathrm{SiO}_{2}$ de Peccerillo and Taylor, 1976), muestran los campos que ocupan las muestras de unidades volcánicas aflorantes en el norte de la Cordillera Occidental y que son las probables unidades fuentes de clastos volcánicos encontrados en los conglomerados de la Formación Guineales.

TABLA 2. Resultados analíticos de óxidos mayores de los clastos de vulcanitas de los conglomerados de la Formación Guineales. (Expresados en wt\%).

\begin{tabular}{lccccccccccc}
\hline Muestra & $\mathbf{F e}_{2} \mathbf{O}_{3}$ & $\mathbf{T i O}_{2}$ & $\mathbf{A l}_{2} \mathbf{O}_{3}$ & $\mathbf{S i O}_{2}$ & $\mathbf{N a}_{2} \mathbf{O}$ & $\mathbf{K}_{2} \mathbf{O}$ & $\mathbf{C a O}$ & $\mathbf{M g O}$ & $\mathbf{M n O}$ & $\mathbf{P P C}$ & SUMA \\
\hline 900624 & 7,81 & 1,48 & 16,4 & 55 & 6,85 & 0,48 & 7,06 & 2,89 & 0,16 & 1,5 & 99,64 \\
900625 & 8,77 & 1,72 & 15,5 & 51,9 & 4,24 & 4,79 & 6,15 & 3,3 & 0,19 & 2,98 & 99,59 \\
900626 & 7,84 & 1,31 & 16,2 & 57,5 & 2,66 & 4,24 & 5,26 & 2,71 & 0,18 & 1,98 & 99,94 \\
900627 & 6,23 & 0,97 & 15,2 & 57 & 2,25 & 7,43 & 4,67 & 1,88 & 0,12 & 3,76 & 99,54 \\
900631 & 16,99 & 2,81 & 11,2 & 46,6 & 2,17 & 0,21 & 7,83 & 4,52 & 0,17 & 6,55 & 99,04 \\
900632 & 10,74 & 1,18 & 12,9 & 49,5 & 2,18 & 0,57 & 10,6 & 7,13 & 0,18 & 4 & 99,04 \\
900633 & 6,31 & 1,37 & 15,2 & 58 & 4,79 & 5,38 & 5,84 & 1,49 & 0,19 & 1,4 & 99,95 \\
900634 & 10,58 & 1,73 & 15,2 & 50,1 & 2,42 & 3,67 & 9,16 & 3,7 & 0,18 & 2,45 & 99,13 \\
900635 & 5,73 & 0,69 & 17 & 56,1 & 2,25 & 6,02 & 4,67 & 2,23 & 0,14 & 4,93 & 99,73 \\
900639 & 11,63 & 1,68 & 10,9 & 45,6 & 4,34 & 1,23 & 9,48 & 3,72 & 0,25 & 9,5 & 98,28 \\
\hline
\end{tabular}


En la FIGURA 5A, que corresponde al diagrama TAS, las muestras GR-6500B y GR-65001C grafican dentro del campo de andesitas subalcalinas, la muestra GR6500B cae cerca del campo del Complejo Santa CeciliaLa Equis, mientras la muestra GR-65001C cae dentro de las rocas volcánicas de este campo; las demás muestras

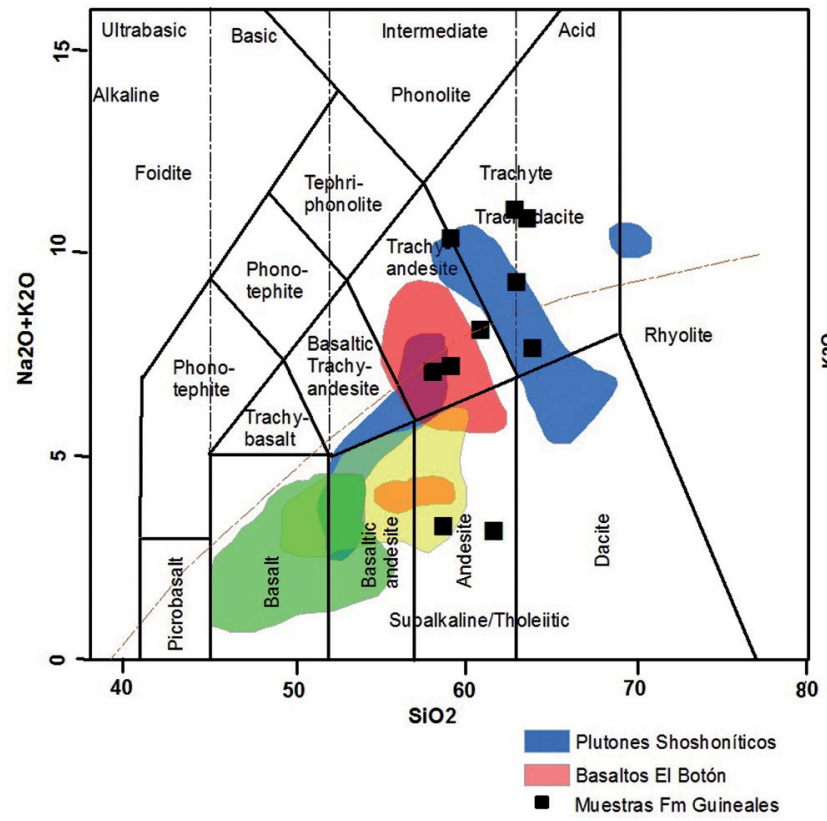

(MIA-398-0, MIA-400-15, MIA-407-31, MIA-424-84, GR-6502B, GR-6504, GR-6506A y JGB-336) caen en el campo de los Basaltos de El Botón y en el campo de los plutones del Arco de El Botón, sugiriendo que las muestras provienen de la erosión de la unidad Basaltos de El Botón.

FIGURA 5. A. Diagrama TAS- (Le Bas et al., 1986). B. Diagrama $\mathrm{K}_{2} \mathrm{O}$ vs $\mathrm{SiO}_{2}$ (Peccerillo and Taylor, 1976), con áreas de localización de muestras de las unidades volcánicas del norte de la Cordillera Occidental y de plutones del Arco de El Botón.

En el diagrama de $\mathrm{K}_{2} \mathrm{O}-\mathrm{SiO}_{2}$ de Peccerillo and Taylor (1976) (FIGURA 5B), las muestras GR-6500B, GR65001C y MIA-398-0 grafican dentro del campo de la serie toleítica, con contenido bajo en K y calcoalcalina con contenido medio de K. Las muestras GR-65001C y MIA-398-0 caen dentro del campo de las vulcanitas del Complejo Santa Cecilia - La Equis y la muestra GR-6500B está dentro del campo de las Diabasas de San José de Urama, cerca de la intersección de los campos de Basaltos de El Botón y el Complejo Santa Cecilia - La Equis. Las demás muestras (MIA-400-15, MIA-407-31, MIA-424-84, GR-6502B, GR-6504, GR6506A y JGB-336) están dentro del campo de la serie shoshonítica y dentro de las áreas del Basalto de El Botón y los plutones de este arco. Petrográficamente, las muestras MIA-400-15, MIA-407-31, MIA-424-84, GR6502B, GR-6504, GR-6506A y JGB-336 corresponden a basaltos porfídicos y tobas similares en textura y composición con las vulcanitas de este arco.

Comparando los datos de petrografía (TABLA 3) y litogeoquímica, las muestras del segmento 8 (GR6500B, GR-65001C) se clasifican como diabasas (FIGURA 6A y B) y tienen afinidad con el campo de las Diabasas de San José de Urama (FIGURA 5B), mientras la muestra MIA-398-0 del segmento 9 corresponde a una toba lítico cristalina (FIGURA 6C) cercana al campo del Complejo Santa Cecilia - La Equis.

Los resultados geoquímicos de óxidos mayores (TABLA 2) y la petrografía (TABLA 3) de vulcanitas, sugieren que estos clastos presentes en los conglomerados de la Formación Guineales provienen de la erosión de la unidad Basalto de El Botón (siete muestras), en menor grado corresponden a la unidad Diabasas de San José de Urama (dos muestras) y una sola muestra podría corresponder al Complejo Santa Cecilia - La Equis o al arco cretácico que genero las rocas de la Formación Barroso (una muestra).

Los resultados químicos obtenidos en clastos de vulcanitas de la Formación Guineales indican que la edad de la Formación Guineales es más joven que la edad del Arco de El Botón (9 - $12 \mathrm{Ma}$ ), es decir, se depositó entre el Mioceno tardío y el Plioceno. De acuerdo a los resultados obtenidos, el mayor aporte de clastos 
volcánicos provino de los Basaltos de El Botón, además, hubo aporte de clastos de las unidades volcánicas que afloran al oriente de la Formación Guineales (Diabasas de San José de Urama) y probablemente de vulcanitas que afloran al occidente, como las del Complejo Santa Cecilia - La Equis.
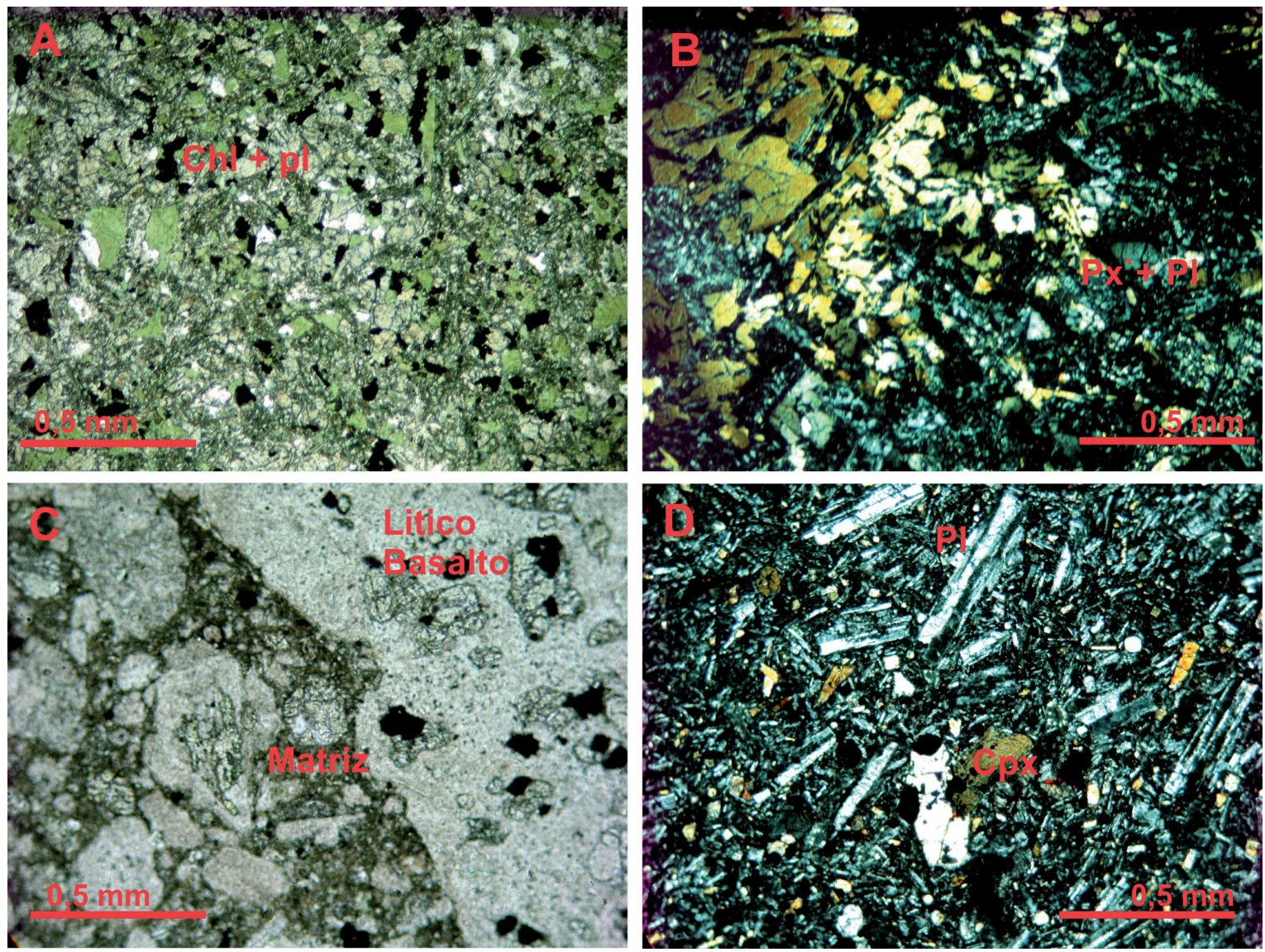

FIGURA 6. Aspecto microscópico de cantos volcánicos de la Formación Guineales. A. GR-6500B. Diabasa. Textura subofítica, amígdalas alteradas a palagonita y clorita. B. GR-6501C. Diabasa. Cristales poiquilíticos de piroxeno con textura ofítica e inclusiones de plagioclasa. C. MIA-398-0. Toba de líticos y cristales. Lítico de basalto con alteración a epidota, matriz microlítica de plagioclasa, olivino y clinopiroxeno. D. MIA-427. Basalto. Roca volcánica constituida por microlitos de plagioclasa, clinopiroxeno (Cpx) y opacos diseminados. Fenocristales de plagioclasa (Pl). Abreviaturas (Siivola and Schmid, 2007).

TABLA 3. Clasificación petrográfica de clastos de vulcanitas de la Formación Guineales.

\begin{tabular}{|c|c|c|c|c|c|c|c|c|c|c|c|c|c|c|c|c|}
\hline IGM & $\mathbf{P l}$ & Ol & Cpx & Opx & Hbl & Chl & Op & Ap & $\mathbf{Z r}$ & Ttn I & Ep & VIDRIO & MATRIZ & FR & OTROS & $\begin{array}{l}\text { CLASIFICACIÓN } \\
\text { PETROGRÁFICA }\end{array}$ \\
\hline 900624 & 32 & 16 & 2 & & & & 5 & & & 1 & & 5 & 15 & 22 & 2 & $\begin{array}{l}\text { TOBA DE LÍTICOS Y } \\
\text { CRISTALES }\end{array}$ \\
\hline 900625 & 25 & 10 & & 5 & & $\mathrm{TR}$ & 1 & & TR & 2 & & 15 & 40 & & & ANDESITA \\
\hline 900626 & 14 & 3 & 1 & & 5 & 2 & & & & 1 & 12 & 10 & 50 & & 3 & $\begin{array}{l}\text { BASALTO CON } \\
\text { URALITIZACIÓN }\end{array}$ \\
\hline 900627 & 13,6 & & 5,64 & & & & 0,5 & TR & & & & & 75,7 & & 4,6 & BASALTO PORFÍDICO \\
\hline 900628 & 47 & 2 & 15 & & & & 6 & & & & & 5 & 25 & & & BASALTO PORFÍDICO \\
\hline 900631 & 55,6 & & 37,1 & & & & 3,2 & & & & & & & & 12,1 & DIABASA \\
\hline 900632 & 57 & & 38 & & & $\mathrm{X}$ & TR & & & TR & & $\mathrm{X}$ & & & 5 & DIABASA \\
\hline 900633 & 44,2 & & 9,2 & & & & & & & & & 13,6 & 92 & & & BASALTO TRAQUITOIDE \\
\hline 900634 & 43,7 & 1 & 22,1 & & & & & & & & & 12,9 & 64,7 & & & BASALTO PORFÍDICO \\
\hline 900635 & 65 & 1 & 12,8 & & & & 4,3 & & & & & 15,8 & & & 1,1 & ANDESITA \\
\hline
\end{tabular}




\section{Edad y Procedencia de circones detríticos}

Se midieron edades U-Pb en circones de la muestra MIA-419-75 que corresponde a la matriz que soporta los clastos de litología volcánica en el segmento 6 (parte media de la columna estratigráfica). A partir del concentrado en batea fue posible la separación de 40 granos, un número que estadísticamente no es representativo para definir poblaciones de circones pero que si reflejan la edad de los detritos que se sedimentaron en la Formación Guineales.
La morfología de los granos de circón varía de subeuhedral prismáticos a redondeados, incoloros algunos con bordes de color pardo. Las imágenes de catodoluminiscencia evidencian que para algunos granos se presentan bordes oscuros que concuerdan con los granos que registran valores altos de $\mathrm{U}$ en $\mathrm{ppm}$ (FIGURA 7A, B), igualmente se observa desarrollo de zonamientos de aspecto ígneo con bordes lineales (FIGURA7B, C) mientras que otros cristales presentan núcleos interrumpidos con zonas recristalizadas hacia los bordes. (FIGURA 7F).

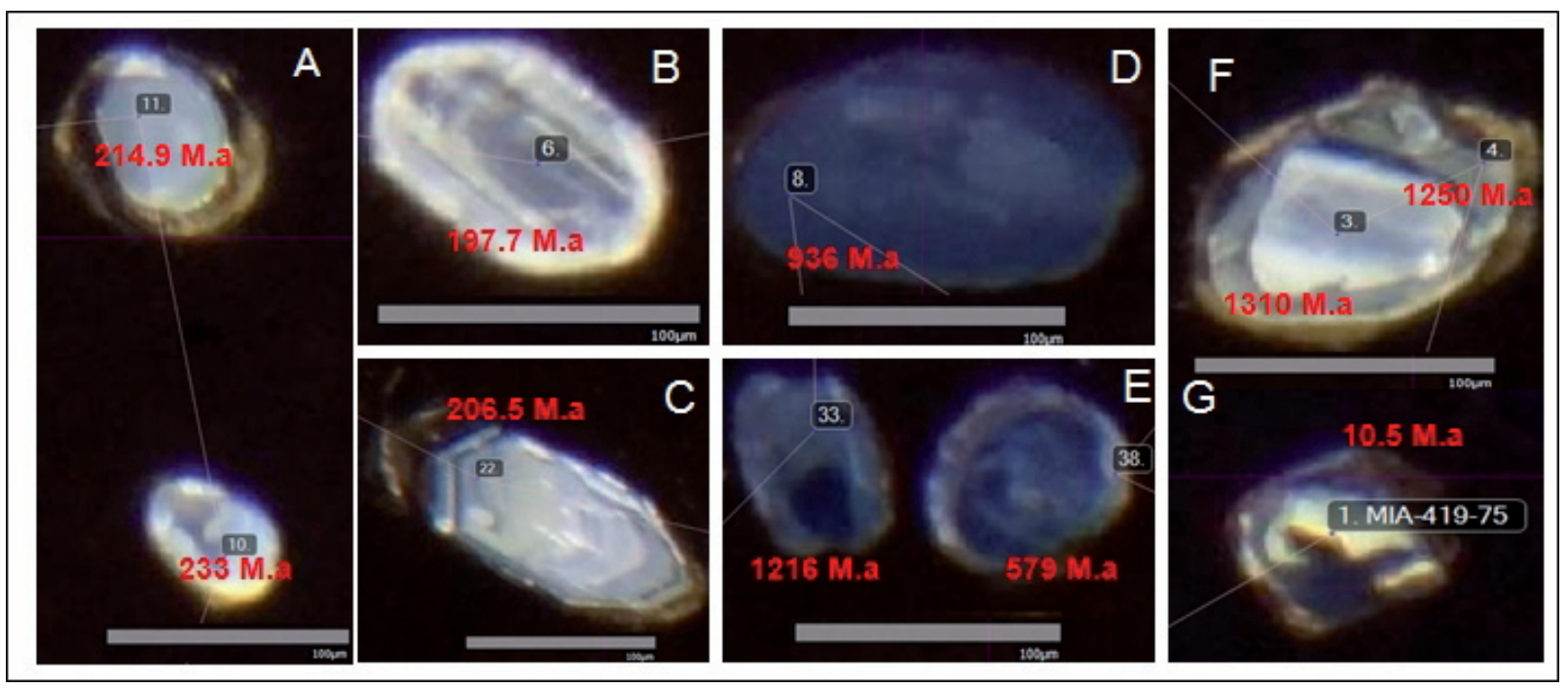

FIGURA 7. Imágenes de catodoluminiscencia de circones detríticos de la Formación Guineales. A. circones redondeados de edad Triásica, familia más representativa. B. y C. circones euhedrales con centros zonados de aspecto ígneo. D. y E. circones de tonalidades anómalas con mayores valores de U en ppm. F. Circón recristalizado. G. grano con bordes irregulares.

Los resultados de la datación U-Pb realizados por el método LA ICPMS (Laser Ablation Inductively Coupled Mass Spectrometry) fueron analizados mediante los diagramas de concordia e histogramas generados en el software de Isoplot vers. 4.15 (Ludwig, 2008), utilizando la relación $\left.\left[\left({ }^{207} \mathrm{~Pb} /{ }^{235} \mathrm{U}\right)-\left({ }^{206} \mathrm{~Pb} /{ }^{238} \mathrm{U}\right) / 206 \mathrm{~Pb} /{ }^{238} \mathrm{U}\right)\right]$ con error $2 \theta$, donde inicialmente se aplicó un filtro y descarte de los granos de circones con discordancias mayores al $10 \%$ para las edades $>$ a 600 Ma y discordancias $>20 \%$ para edades $<$ a $600 \mathrm{Ma}(\mathrm{n}=3)$ con el fin de ajustar y dar mayor confiabilidad al rango de edad (TABLA 4).

La mayoría de los circones se ajustan a la curva de concordia con algunos granos discordantes cerca de los $600 \mathrm{Ma}$. Los granos muestran edades que abarcan desde el Mioceno para un circón con una edad de 10,5 Ma (n=1); Cretácico 76,4 Ma ( $\mathrm{n}=1)$; Jurásico temprano 197,7 Ma ( $\mathrm{n}=1)$; Triásico medio siendo el intervalo de granos más representativo con un pico entre los 206,5 a los $287 \mathrm{Ma}(\mathrm{n}=15)$; otros de 479 a $480 \mathrm{Ma}$ del Ordovícico temprano $(\mathrm{n}=2)$; Neoproterozoico de $550 \mathrm{Ma}(\mathrm{n}=4) ; 648 \mathrm{Ma}(\mathrm{n}=1)$ y $936 \mathrm{Ma}(\mathrm{n}=1)$; y Mesoproterozoicos de edad Grenvilliana con intervalos entre 1.073 a $1.079 \mathrm{Ma}(n=3), 1.216$ a $1.250 \mathrm{Ma}(\mathrm{n}=5)$, otra edad de 1.357 Ma dada por $(\mathrm{n}=1)$, y el intervalo de 1.509 y $1.599 \mathrm{Ma}(\mathrm{n}=2)$, el cual se muestra acorde con la curva de concordia infiriendo claramente la presencia de este antiguo material en la depositación de la Formación Guineales. Los circones muestran relaciones Th-U (FIGURA 8) en promedio de 0,36 ppm, un solo circón de edad Miocena (10,5 Ma) presenta relaciones mayores de Th-U de 1,61 ppm.

Hoskin and Schaltegger (2003) presentan patrones que son característicos de las tierras raras para circones detríticos y que resultan comparables con el comportamiento de las 
REE de los circones que se muestran en la TABLA 5. Exhiben un trazo generalizado de pendiente positiva con un empobrecimiento de las LREE con valores menores o iguales a 1 del condrito de McDonough and Sun (1995) y un enriquecimiento progresivo desde las MREE hacia las HREE (FIGURA 9). Los circones de edad de $197 \mathrm{Ma}$ (Zr 046), en la familia triásica 214,9 Ma (Zr 051) y 241,9
Ma (Zr 054) presentan un bajo fraccionamiento desde las tierras raras medias hacia las pesadas sugiriendo posiblemente que el circón no tuvo una influencia notable durante la diferenciación magmática u otra causa de este empobrecimiento puede ser la saturación y el fraccionamiento del granate generando patrones planos hacia las HREE (Hoskin and Schaltegger, 2003).
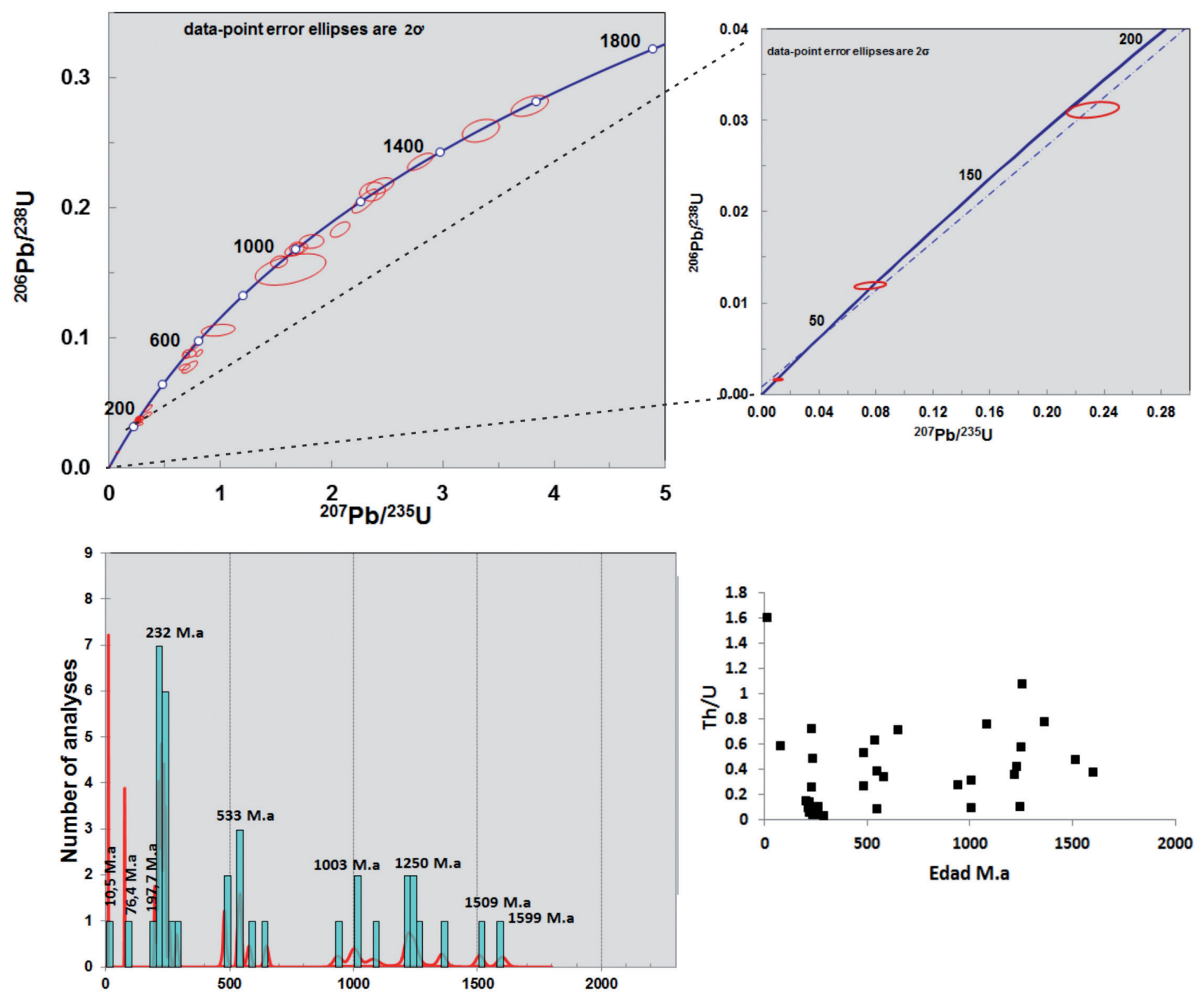

FIGURA 8. Diagramas de concordancia, histograma de distribución de edad relativa y relación Th-U de los circones detríticos de la Formación Guineales.

Dentro del intervalo del Ordovícico inferior se muestra una traza anómala del circón 056 (480Ma) que puede estar asociada a alteraciones del grano, Belousova et al. (2002) reportan altas concentraciones de REE para granos con procesos metamícticos. En general se presenta anomalía negativa del europio con un relación promedio de $\mathrm{Eu} / \mathrm{Eu}^{*}$ de 0,21 excepto para los circones 056 y 065 de edades de $480 \mathrm{Ma}$ y $542 \mathrm{Ma}$, respectivamente, y una anomalía positiva de Ce con valores mayores para el circón 041 de $10 \mathrm{Ma}$, con enriquecimiento de 469 ppm, esto debido probablemente a inclusiones de monacita y/o xenotima los cuales albergan altas concentraciones de Cerio. Las relaciones de $(\mathrm{Lu} / \mathrm{Gd})_{\mathrm{N}}$ son de 31,76 y $(\mathrm{Sm} / \mathrm{La})_{\mathrm{N}}$ de 171 , valores de itrio $(\mathrm{Y})$ de $1110 \mathrm{ppm}$ y de Hf de alrededor de 13.449 ppm. 
Las edades Triásicas que predominan en circones detríticos de la muestra analizada para la Formación Guineales pueden representar un aporte de las rocas metamórficas asociadas a la Cordillera Central (Paragneis migmatítico de la Palmas, Neis augen de las Palmas (Martens et al., 2014), Neis de Palmitas (Vinasco et al., 2006) y Migmatita del neis de Las Palmas (Ordóñez-Carmona, 2001). Igualmente, edades del Neoproterozoico (550 Ma, 648 Ma y $936 \mathrm{Ma}$ ) y Mesoproterozoico (1.073, 1.079, 1.216, 1.250, 1.357, 1.509 a 1.599 Ma pueden inferir una contribución de
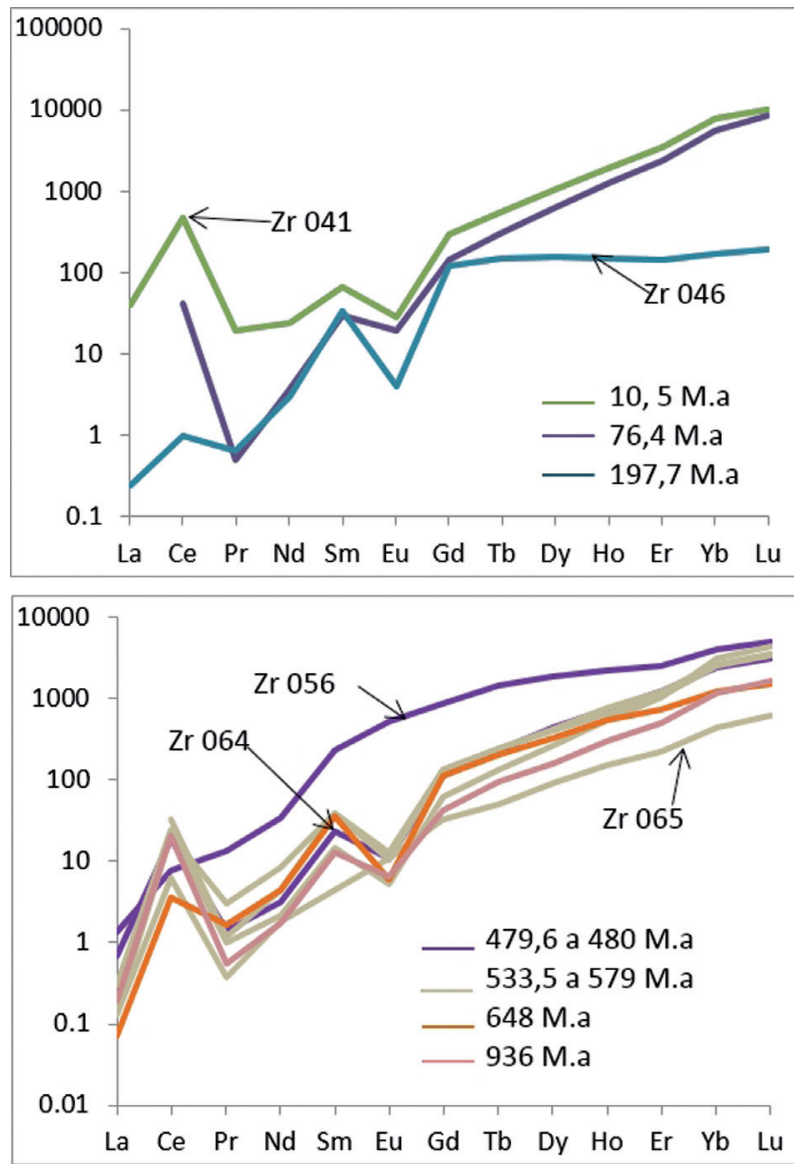

material de basamento metamórfico precámbrico de la Cordillera Central.

La edad más reciente que arroja los circones de la muestra estudiada es del Mioceno (10,5 Ma) y concuerda con el intervalo de edades que se presenta para el Arco del Botón entre 9 y 12 Ma (Zapata y Rodríguez, 2012). Teniendo en cuenta su posición tectónica y su afinidad en los análisis multi-método desarrollados en este estudio, puede significar aporte de esta unidad en la cuenca de la Formación Guineales.
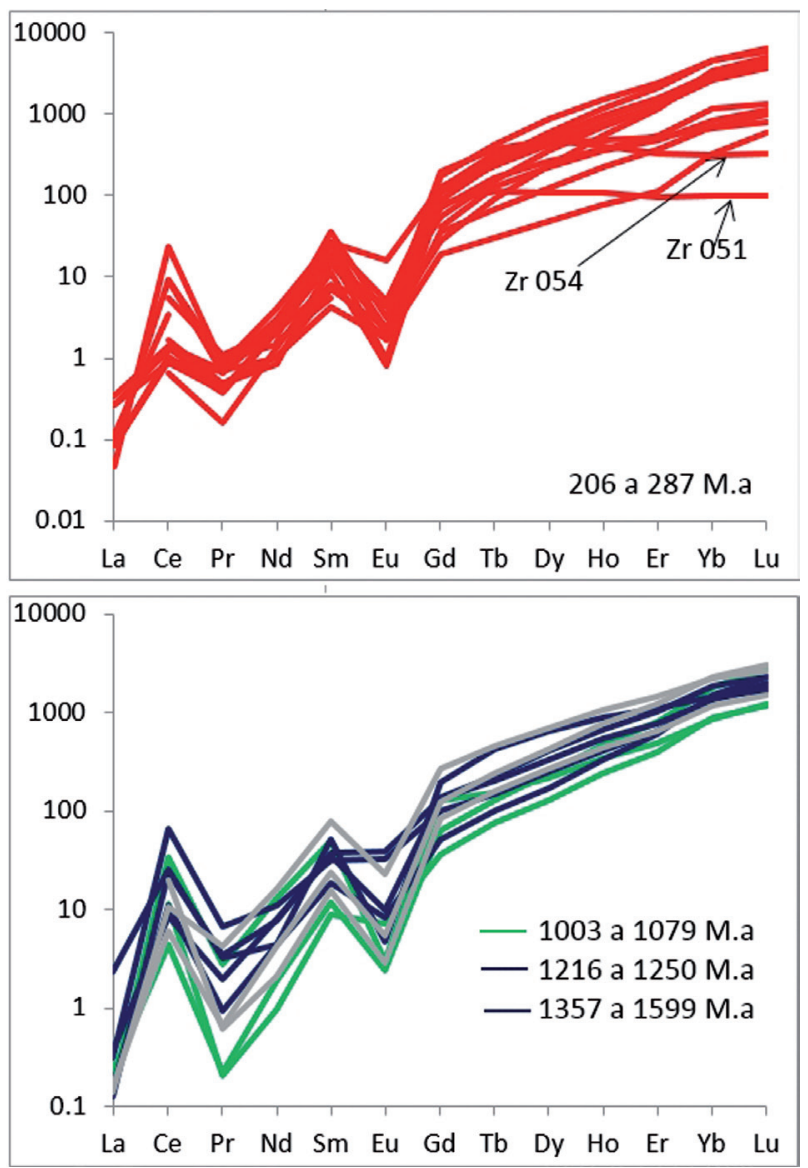

FIGURA 9. Diagramas de elementos traza normalizados a condrito (McDonough and Sun, 1995).

La edad Cretácico de 76,4 Ma (n=1) en un circón, podría ser asociado a alguno de los pulsos del magmatismo cretácico que generó, por ejemplo, el Batolito Antioqueño; y por último el circón que reporta una edad Jurásico temprano 197,7 Ma $(\mathrm{n}=1)$ es más compleja de asociar a alguna unidad, pues los eventos jurásicos están menos definidos en la evolución de los Andes del Norte y corresponden a eventos magmáticos de arco relacionados a cuatro pulsos (Leal, 2011), sin que se halla establecido las unidades jurásicas relacionadas a cada pulso magmático. Además, existen eventos de metamorfismo regional poco conocidos que apenas comienzan a salir en algunos trabajos o están previos a ser publicados, a los cuales se podría relacionar también este circón, por tal razón, un solo dato es difícil de asociar en estos momentos a una unidad en particular. 


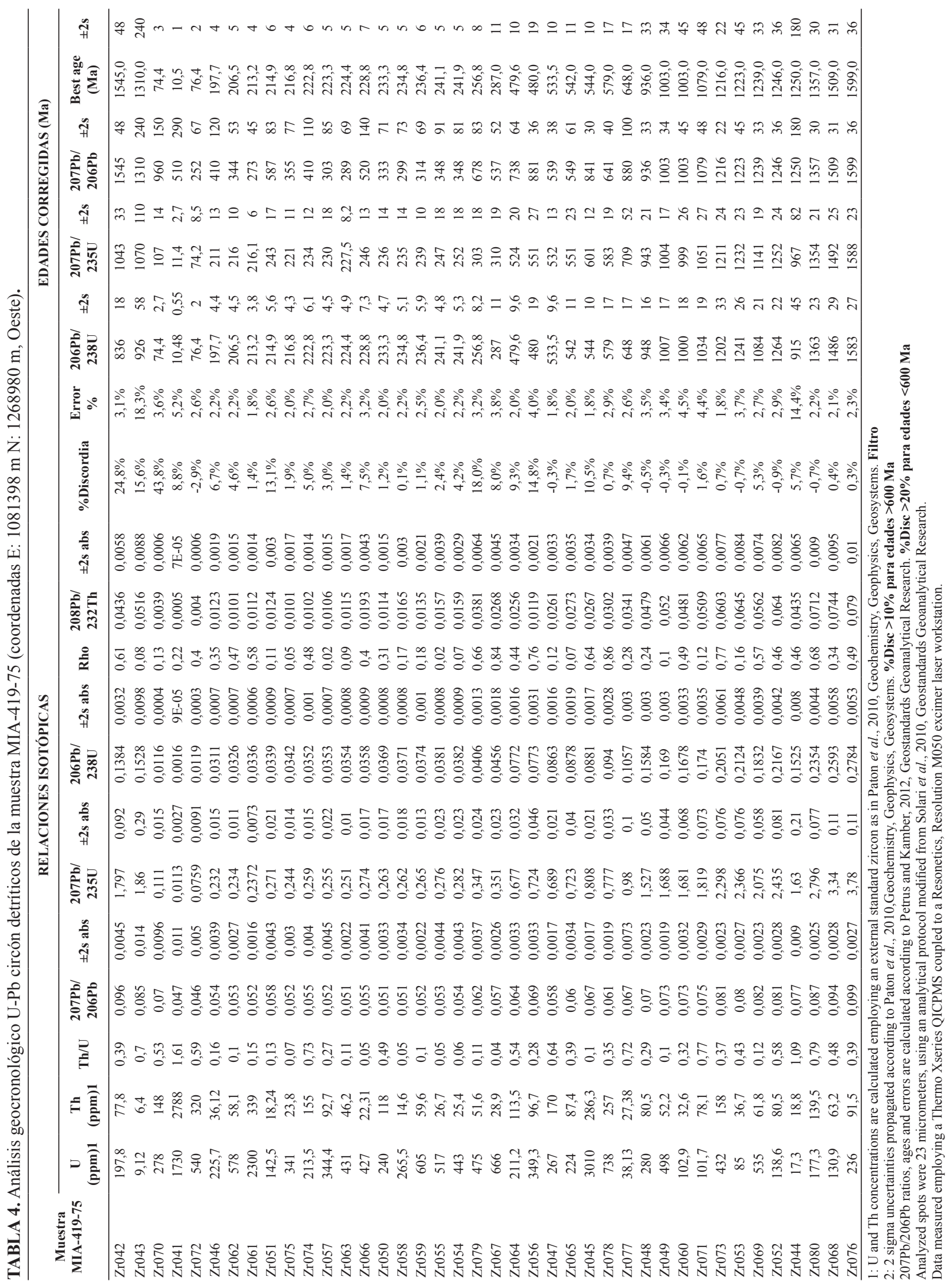




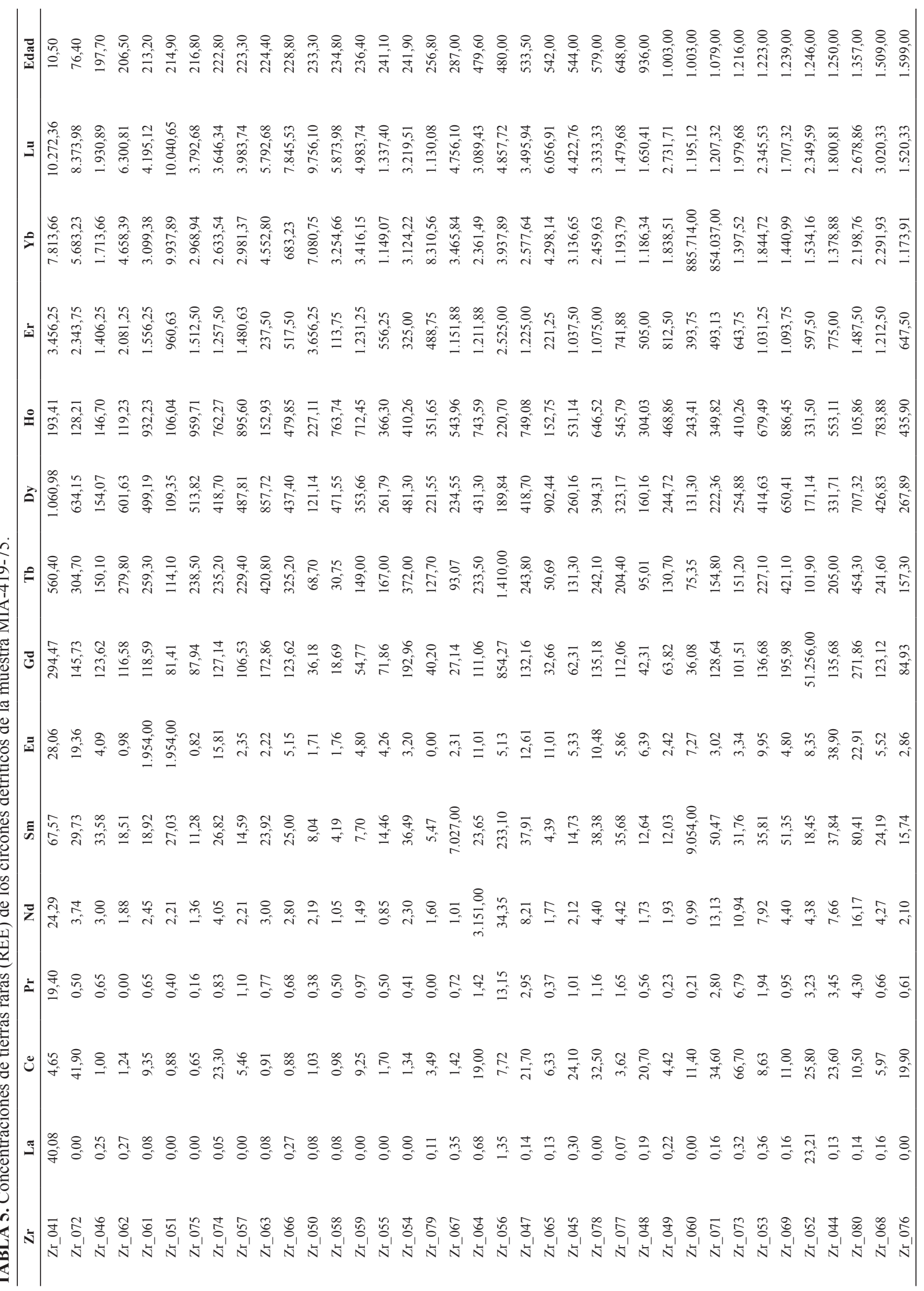




\section{Consideraciones adicionales sobre probable procedencia de cantos de chert, calizas y areniscas}

Se hizo análisis petrográfico a cinco (5) clastos de caliza, las cuales se clasifican como micritas, biomicritas y micritas oolíticas (TABLA 6). Las unidades que tienen calizas y afloran en la parte norte de la Cordillera Occidental, que podrían aportar clastos de calizas a la Formación Guineales, corresponden a la unidad Chert y Calizas de Nutibara de edad Cretácico tardío (Rodríguez et al., 2010) y la unidad Sedimentitas de Cruces de Edad Eoceno (Rodríguez et al., 2014). Mientras, los clastos de chert se asocian a la unidad Chert y calizas de Nutibara (Rodríguez et al., 2010), única unidad con capas de chert en este sector de la Cordillera Occidental.

El registro fósil de la unidad Chert y Calizas de Nutibara corresponde a restos de foraminíferos, radiolarios, espículas reemplazadas por carbonato (?) y ostrácodos (?), reemplazados por calcita esparítica; predominan los fósiles de forma circular o discoidal con la concha delgada; el tamaño promedio de los restos fósiles es de $0,04 \mathrm{~mm}$ a $0,25 \mathrm{~mm}$, con las caparazones reemplazadas por calcita en algunos casos fibrosa; ooides y peloides de forma circular, con estructura concéntrica o sin estructura a manera de calciesferas de tamaños generalmente menores a 0,16 $\mathrm{mm}$, los cuales flotan en la matriz micrítica (Rodríguez et al., 2010) (FIGURA 10C).

De otra parte, el registro fósil de las Sedimentitas de Cruces corresponde a Globigerinatheka sp. (?), Planorotalites sp. (?), Nuttallides sp. (?)Eponides sp. , Cibicidoides sp. (?), Gyroidinoides (?), Uvigerina sp. (?), Lenticulina sp. (?), Bulimina sp. (?) ,Eponides sp. \|(?), Shiphonodosaria sp. (?),Eponides sp. Y Karreriella sp. (Buchely et al., 2009). En la FIGURA 10D se muestra una caliza típica con la fauna fósil que frecuentemente aparece en las Sedimentitas de Cruces.

Los cinco clastos de calizas de la Formación Guineales, a los cuales se les realizó sección delgada, tienen aloquímicos que corresponde a ooides y restos fósiles de foraminíferos, radiolarios, espículas reemplazadas por carbonato (?) y calciesferas reemplazados por calcita; predominan los fósiles de forma circular o discoidal con la concha delgada de espesor menor a $0,02 \mathrm{~mm}$, reemplazadas las cámaras por calcita dentro de una matriz micrítica (FIGURA 10 A y B).

TABLA 6. Clasificación petrográfica de clastos de calizas dentro de la Formación Guineales.

\begin{tabular}{lcccccl}
\hline IGM & Qtz & ALOQ. & ORTOQUI & OTROS & TEXTURA & CLASIFICACIÓN PETROGRÁFICA \\
\hline 900603 & 3 & 1 & 95 & 3 Poros & MUDSTONE & MICRITA \\
900604 & 1 & & 98 & 2 peloides & MUDSTONE & MICRITA \\
900607 & TR & 6,6 & 93,4 & & MUDSTONE & MICRITA OOLITICA \\
900609 & & 10,1 & 89,9 & & WACKSTONE & MICRITA FOSILIFERA \\
900610 & & 15 & 85 & & WACKSTONE & BIOMICRITA RALA \\
\hline
\end{tabular}

Al comparar la composición, texturas y registro fósil de los clastos de caliza de la Formación Guineales con la fauna fósil de las unidades Chert y Calizas de Nutibara y Sedimentitas de Cruces (descrita en Rodríguez et al., 2014; Buchely et al., 2009); se encuentra que tanto la litología como el registro fósil de los clastos de la Formación Guineales es comparable con las calizas de la unidad Chert y Calizas de Nutibara. No se encontró en estos cinco clastos registro fósil comparable a las calizas de las Sedimentitas de Cruces, sin que se pueda descartar con este número limitado de muestras la no existencia de aporte de calizas de las Sedimentitas de Cruces. Teniendo en cuenta que no se encontró un registro fósil guía que permita una asociación contundente con alguna unidad específica, se hace la relación por similitud de los fósiles y los tipos de caliza presentes en cada unidad.

Clastos de arenisca: para un primer acercamiento a las probables unidades fuentes o procedencia de clastos de areniscas, se analizaron cuatro secciones delgadas, cuyos resultados petrográficos se resumen en la TABLA 7 y se muestran en las FIGURA 11 y12. Se debe tener en cuenta que es un número limitado de muestras que aportan información preliminar sobre probables unidades fuente de los clastos de areniscas de la Formación Guineales. 

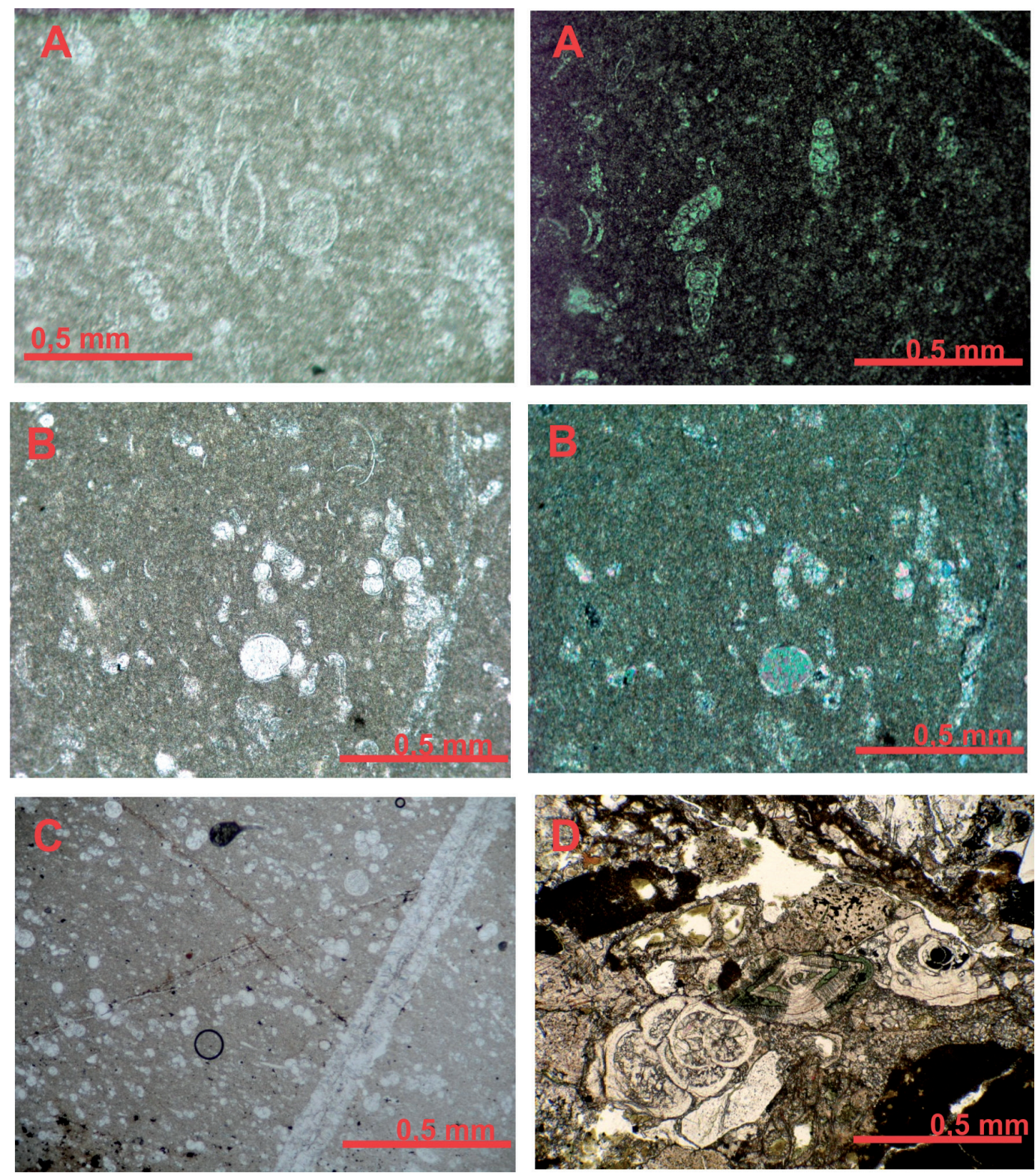

FIGURA 10. Aspecto microscópico de calizas de diferentes unidades en la parte norte de la Cordillera Occidental. A. y B. Clastos de caliza de la Formación Guineales. C. Calizas de la unidad Chert y Calizas de Nutibara (Tomada de Rodríguez et al., 2010). D. Aspecto microscópico y fauna de foraminíferos de la unidad Sedimentitas de Cruces (Rodríguez et al., 2014).

Las unidades que podrían aportar clastos de areniscas a la Formación Guineales corresponden a las Sedimentitas de Cruces y a las Litoarenitas, Limolitas y Lodolitas de Urrao. Las Sedimentitas de Cruces están constituidas por sublitoarenitas y litoarenitas con fragmentos de cuarzo, feldespato, micas, opacos, circón, epidota y líticos de rocas sedimentarias y volcánicas; intercaladas con biomicritas con textura wackestone, bioesparitas arenosas con textura grainstone y lodolitas arenosas calcáreas. La unidad Litoarenitas, Limolitas y Lodolitas de Urrao esta compuesta por arcosas, arcosas líticas, grawacas, limolitas y lodolitas silíceas.
La clasificación petrográfica, de los cuatro clastos de areniscas de la Formación Guineales, se grafica y compara en el triangulo de Folk (1974), con el campo definido a partir del análisis petrográficos de 30 areniscas de la unidad Litoarenitas, Limolitas y Lodolitas de Urrao, descritas en Rodríguez et al. (2014). Conjuntamente se grafican cuatro análisis petrográficos de areniscas de la unidad Sedimentitas de Cruces, tomadas del trabajo de Rodríguez et al. (2014) (FIGURA 9). 
TABLA 7. Clasificación petrográfica de clastos de areniscas dentro de la Formación Guineales.

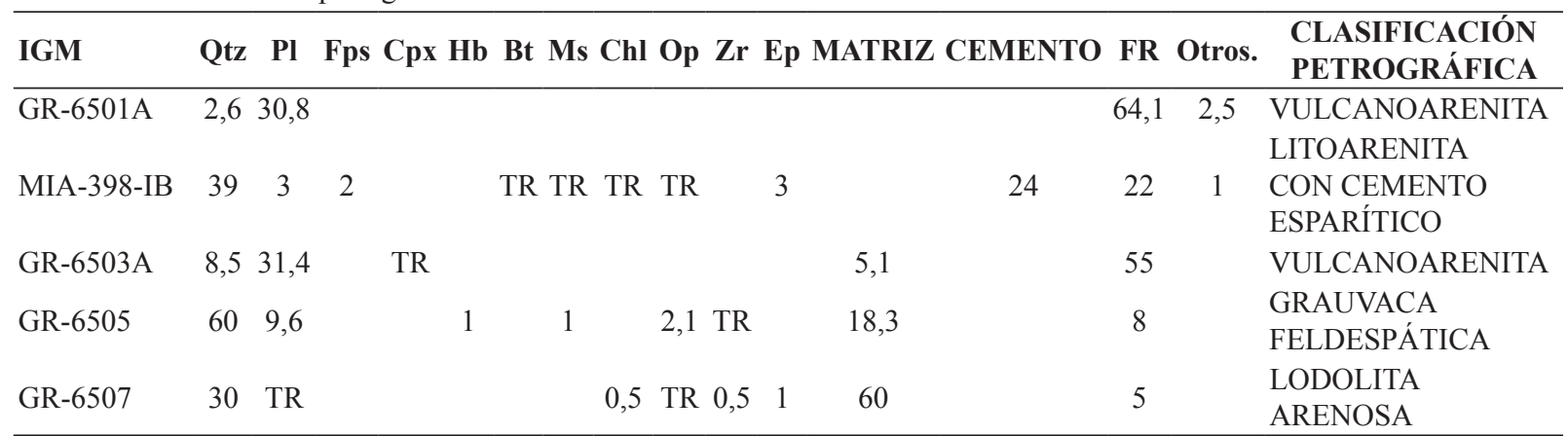
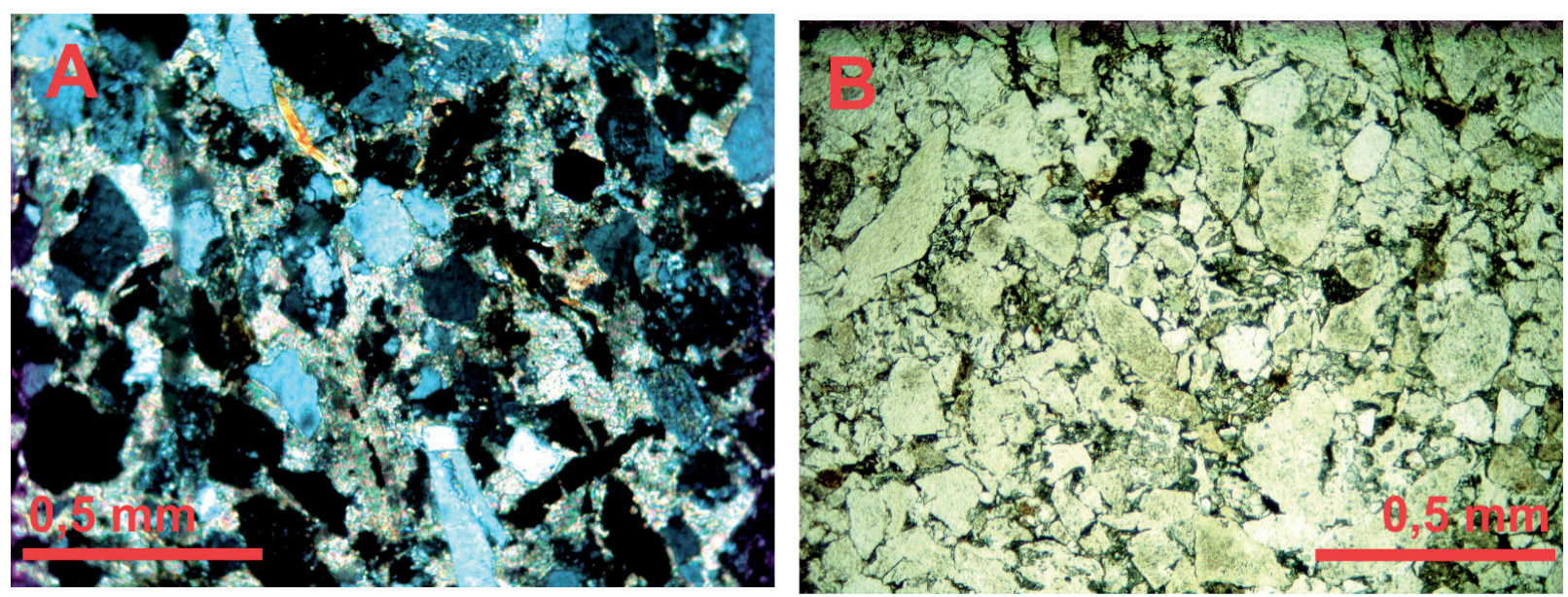

FIGURA 11. A. MIA-398-IB. Litoarenita. Terrígenos subangulares de cuarzo monocristalino, láminas de sericita, líticos sedimentarios, bioclastos de foraminíferos en cemento esparítico. B. GR-6503A. Volcanoarenita feldespática. Roca clástica compuesta por terrígenos subangulares de plagioclasa y líticos volcánicos.

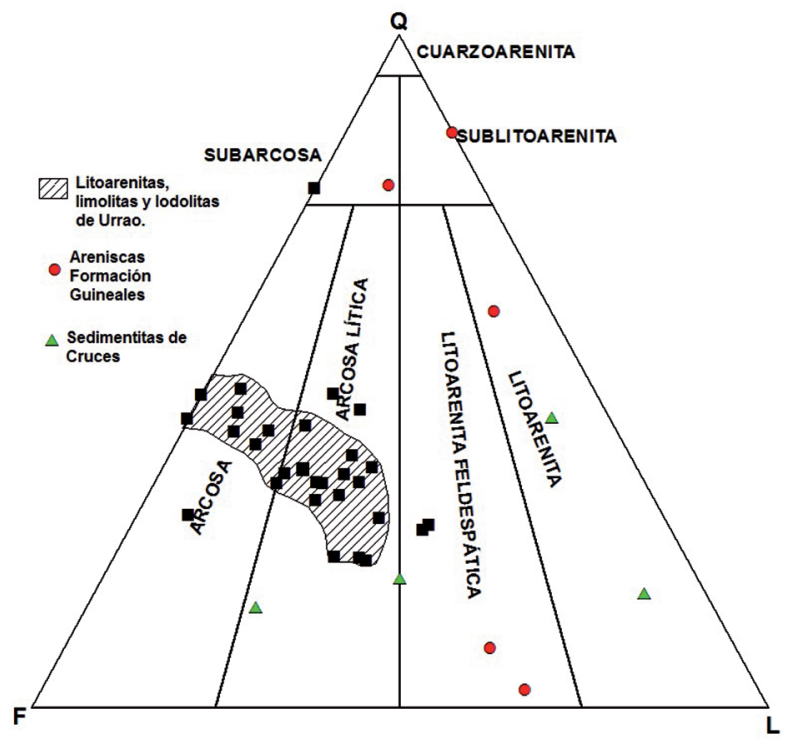

FIGURA 12. Triángulo de clasificación de areniscas de Folk (1974). En negro el campo composicional de la unidad Litoarenitas, Limolitas y Lodolitas de Urrao, en verde muestras de areniscas de la unidad Sedimentitas de Cruces y en rojo muestras de clastos de areniscas de la Formación Guineales.
En la FIGURA 12 se muestra que ningún clasto de arenisca analizado de la Formación Guineales cae dentro del campo composicional de las areniscas de la unidad Litoarenitas, Limolitas y Lodolitas de Urrao, pero no se puede asegurar que corresponden a areniscas de la unidad Sedimentitas de Cruces, aunque muestren una mejor correlación composicional con esta unidad. Los pocos análisis petrográficos de clastos de areniscas de la Formación Guineales son insuficientes para una mejor correlación litológica, unido al número reducido de análisis petrográficos de areniscas de la unidad Sedimentitas de Cruces reportados en los trabajos de Rodríguez et al. (2014) y Buchely et al. (2009), que no permiten generar un campo composicional en el triángulo de Folk.

\section{CONTACTOS, EDAD Y AMBIENTE}

Los contactos de la Formación Guineales están cubiertos por depósitos de vertiente sobre la vía Dabeiba-Mutatá; la unidad reposa discordante sobre Basaltos de El Botón y al oriente cabalga el Basalto de El Botón sobre la parte superior de la Formación Guineales. 
La edad de la Formación Guineales se obtiene de forma indirecta, de acuerdo a las relaciones estratigráficas se puede afirmar que la Formación Guineales es posterior a la unidad Basalto de El Botón con edades Ar-Ar entre 9 y 12 Ma (Zapata y Rodríguez, 2012), no siendo más vieja que el Mioceno tardío. Los resultados obtenidos con base en la química de clastos y en un circón detrítico, indican que la unidad tuvo aporte de los Basaltos de El Botón.

Un análisis de palinomorfos en la muestra JGB-340, con presencia de restos de hojas, arrojó un kerógeno de origen continental que ha sufrido alteración térmica, con recobro muy pobre de palinomorfos mal preservados: Psilatriletes, Deltaidospora, Polypodiisporites $s p$. y esporas de hongos con muy amplia distribución estratigráfica, sin que se pueda determinar la edad de la Formación Guineales con palinomórfos en este trabajo.

Los paquetes de conglomerados clasto soportados, mediana a pobremente seleccionados con algo de matriz arenosa entre los clastos, indican un régimen de energía intermedio a alto con predominio de espesos paquetes de gravas. Los escasos niveles de arenas son producto de los periodos de baja energía, dentro de un sistema fluvial. Los materiales que conforman los conglomerados de la Formación Guineales se acumularon discordantes sobre vulcanitas del Basalto de El Botón, probablemente en un ambiente de abanicos aluviales y ríos trenzados, depositados en una zona de piedemonte en la cual drenaban los ríos en sentidos Este Oeste y Oeste - Este, como lo sugiere el estudio de proveniencia de los cantos de naturaleza volcánica, con aporte de unidades litológicas que se encuentran al oriente y al occidente de la unidad.

La sedimentación se dio en la zona de colisión del Bloque Cañasgordas al oriente y el Bloque Chocó-Panamá al occidente; representa un evento de levantamiento, erosión y acumulación en un ambiente continental, donde ambos bloques estaban levantados por encima del nivel de sedimentación de la cuenca donde se acumuló la Formación Guineales.

\section{CONCLUSIONES}

La Formación Guineales había sido considerado en trabajos anteriores de edad Eoceno (Muñoz y Zapata., 1987; Rodríguez et al., 2010; Buchely et al., 2009), problema que surgió de la falta de una columna estratigráfica de la unidad cuando fue descrita por Botero (1936). Trabajos posteriores asumieron dentro de la Formación Guineales otras unidades y litologías sedimentarias con presencia de microfósiles eocenos, como la unidad Sedimentitas de Cruces, que afloran en la misma zona de colisión de los Bloques Cañasgordas y Choco-Panamá, en el sector de Dabeiba.-Antioquia y que reposa discordante sobre el Complejo Santa Cecilia - La Equis. El levantamiento de la columna estratigráfica permite concluir que estas dos unidades son de diferente composición, edad y origen y están descansando sobre rocas volcánicas diferentes.

Se consideró, hasta antes del presente trabajo, que el substrato de la Formación Guineales eran las vulcanitas del Complejo Santa Cecilia - La Equis, sin embargo, trabajos recientes han permitido separar una nueva unidad de rocas volcánicas en este sector de la Cordillera Occidental, denominada Basaltos de El Botón, con edades Ar-Ar entre 9 y 12 Ma (Zapata y Rodríguez, 2011; Rodríguez y Zapata, 2012) en donde reposa la Formación Guineales, indicando que la edad de la Formación Guineales es posterior a $9 \mathrm{Ma}$.

Los análisis de procedencia multi-método utilizado en este trabajo se presenta como un conjunto de métodos complementarios con resultados diferentes en cada uno de ellos, pero que en conjunto permiten sugerir algunas de las unidades de la Cordillera Occidental que aportaron clastos a los conglomerados de la Formación Guineales:

- Los análisis geoquímicos (óxidos mayores) adelantados en clastos volcánicos sugieren que el aporte de clastos volcánicos corresponde a las unidades Basaltos de El Botón, Diabasas de San José de Urama y probablemente el Complejo Santa Cecilia -La Equis, información que unida a la descripción petrográfica de los clastos de vulcanitas, apoya algunos resultados, como es el caso de la unidad Diabasas de San José de Urama, única unidad en este sector de la cordillera con diabasas espilitizadas y que está en concordancia con los datos de petrografía especifica de dos (2) clastos.

- La clasificación petrográfica de clastos de areniscas y la comparación con los campos de areniscas de las unidades Litoarenitas, Limolitas y Lodolitas de Urrao y Sedimentitas de Cruces, indica que ningún clasto analizado de la Formación Guineales cae dentro del campo composicional de las areniscas de la unidad Litoarenitas, Limolitas y Lodolitas de Urrao, pero tampoco se puede asegurar con certeza que corresponden a areniscas de la unidad Sedimentitas de Cruces, aunque muestren una mejor correlación composicional.

Los análisis de procedencia muestran, que si bien los clastos conglomeráticos presentan una proveniencia local de unidades circundantes de las unidades que 
afloran al este y al oeste de la Formación Guineales, los circones de la fracción matriz de un conglomerado del segmento 6 provienen del basamento metamórfico de la Cordillera Central.

Se esperaba que los resultados del análisis U-Pb en circones corroborara los resultados de la geoquímica y la petrografía de los clastos, pero los resultados muestran que el área fuente principal de los circones es el basamento metamórfico de la Cordillera Central y solo un circón presenta una edad de 10,5 Ma sugiere correspondencia con el magmatismo de los Basaltos de El Botón. Este comportamiento puede explicarse debido a la pobre cantidad de circones que pueden aportar unidades de composición basáltica

La proveniencia de circones del basamento de la Cordillera Central (Complejo Cajamarca) podría ser interpretada en dos sentidos: el primero es que los circones sean retrabajados de unidades sedimentarias anteriores que tuvieron aporte de la Cordillera Central y que afloran en la Cordillera Occidental, por ejemplo, la Formación Penderisco de edad Cretácico tardío o las Sedimentitas de Cruces del Eoceno; sin embargo no hay estudios de proveniencia de circones en estas dos unidades, por el contrario, en las sedimentitas del Complejo Quebradagrande se ha establecido la proveniencia de circones detríticos del basamento de la Cordillera Central (Pardo et al., 2011). En segundo lugar se podría pensar que los ríos drenaban material del basamento metamórfico de la Cordillera Central y por estar más alejada el área fuente solo llegaron los minerales más resistentes, posibilidad que se ve limitada por la falta de clastos metamórficos y ausencia de cuarzo de origen metamórfico en las areniscas de la Formación Guineales.

\section{AGRADECIMIENTOS}

Se agradece al Servicio Geológico Colombiano, que financió la ejecución de este trabajo. A la geóloga del instituto, Diana María Montoya por la revisión del texto. A los revisores del escrito, doctores Mauricio Parra y José Fernando Duque, que hicieron una minuciosa labor de corrección y aportaron valiosos comentarios para mejorar el texto final del artículo.

\section{REFERENCIAS}

Álvarez, J. 1971. Informe preliminar sobre geoquímica de la Cordillera Occidental. INGEOMINAS. Informe interno (inédito). Medellín.

Álvarez, E., y González, H. 1978. Geología y geoquímica del Cuadrángulo I-7 (Urrao). Escala 1:100.000. INGEOMINAS. Informe 1761.347p. Medellín.
Belousova, E.A., Griffin, W.L., O’Reilly, S.Y., and Fisher, N.I. 2002. Igneous zircon: trace element composition as an indicator of source rock type. Contributions to Mineralogy and Petrology, 143: 602-622.

Botero, G. 1936. Bosquejo de la paleontología colombiana. Tesis de grado, Escuela de Minas, Anales de la Facultad de Minas. Medellín, 116p.

Buchely, F., Parra, E., Castillo, H., González, F., Dávila, C., y Romero, O. 2009. Realización de la cartografía geológica y muestreo geoquímico en las planchas 144, 145, 128, 129, 113 y $114(1580 \mathrm{~km})$. Contrato No. 390 de 2007 INGEOMINAS-GRP Ltda. Bogotá, 172p.

Calle, B., y Salinas, R. 1986. Geología y geoquímica de la Plancha 165, Carmen de Atrato. INGEOMINAS. Informe 1987. Medellín. 140p.

De Porta, J. 1974. Léxico Estratigráfico. Amerique Latine, Colombie, Tertiaire et Quaternaire. Volume $\mathrm{V}$, Fascicule 4b. Union Internationale des Sciences Geologiques.

Eggins, S.M., Kinsley, L.P.J., and Shelley, J.M.G. 1998. Deposition and element fractionation processes occurring during atmospheric pressure sampling for analysis by ICP-MS. Applied Surface Science. 129: 278 - 286.

Folk, R.L. 1974. Petrology of Sedimentary Rocks. The University of Texas, Austin. USA. 184p.

Folk, R.L. 1962. Spectral subdivision of limestone types. In: Ham, W.E. (Ed). Classification of carbonate rocks. American Association of Petroleum Geologists, Symposium Memoir, 1: 62-84.

Folk, R.L 1954. The Distinction between grain size and mineral composition in sedimentary rock nomenclature. Journal of Geology, 62 (4): 344-359.

Hoskin, P.W.O., and Schaltegger, U. 2003. The Composition of zircon and igneous and metamorphic petrogenesis. In: Hanchar, J.M., and Hoskin, P.W.O. (eds). Zircon. Reviews in Mineralogy and Geochemistry, 53: 27-62.

Kosler, J., and Sylvester, P.J.. 2003. Present trends and the future in geochronology: laser ablation ICPMS. In: Hanchar, J.M, and Hoskin, P.W.O. (Eds) Zircon. Reviews in mineralogy and geochemistry, 53: 243-275.

Leal, H., 2011. Phanerozoic gold metallogeny in the colombian Andes: a tectono-magmatic approach. Tesis de Doctorado. Universidad de Barcelona, 989p. 
Le Bas, M.I., Le Maitre R.W., Streckeisen, A., and Zanetin, B. 1986. A chemical classification of volcanic rocks based on the total alkali-silica diagram. Journal of Petrology, 27(3): 745-750.

Ludwig, K., 2008. Isoplot version 4.15: a geochronological toolkit for microsoft Excel. Berkeley Geochronology Center, Special Publication No. 4.

Marshall, D.J. 1988. Cathodoluminescence of geological materials. Unwin Hyman, Londres, 146p.

Martens, U., Restrepo, J.J., Ordoñez - Carmona, O., and Correa, A.M. 2014. The Tahamı' and Anacona Terranes of the Colombian Andes: missing links between the South American and Mexican Gondwana margins. The Journal of Geology, 122: 507-530.

McDonough, W.F., and Sun, S. 1995. The composition of the Earth. Chemical Geology, 120: 223-254.

Mejía, M., and Salazar, G. 1989. (Publicado 2007). Mapa geológico de la plancha 114 Dabeiba, escala 1:100.000. INGEOMINAS. Medellín.

Muñoz, R., y Zapata, G. 1987. Prospección geoquímica regional de la Plancha 114 Dabeiba y parte occidental de la 115 Toledo. INGEOMINAS. Informe 2033. Medellín, 61p.

Ordóñez-Carmona, 2001. Caracterizaçao isotópica $\mathrm{RbSr}$ e $\mathrm{SmNd}$ dos principais eventos magmaticos nos Andes Colombianos. Tesis de doctorado, Universidad de Brasilia, 177p.

Pardo, A., Cardona, A., Silva; J. C., Borrero, C., y Tamayo, J.E. 2011. Geocronología U/Pb en circones detríticos del Complejo Quebradagrande: nuevos datos sobre la procedencia de los sedimentos cretáceos en la margen NW de Suramérica. Poster, XIV Congreso Latinoamericano de Geología. Medellín.

Peccerillo, A., and Taylor, S.R. 1976. Geochemistry of Eocene calc-alkaline volcanic rocks from Kastamonir area, Northern Turkey. Contributions to Mineralogy and Petrology, 58: 63-81.

Rodríguez, G., y Arango, M.I. 2013. Formación Barroso: arco volcanico toleitico y diabasas de San José de Urama: un prisma acrecionario T-Morb en el segmento norte de la Cordillera Occidental de Colombia. Boletín Ciencias de la Tierra, 33: 17-38.

Rodríguez, G., y Zapata, G. 2012. Características del plutonismo Mioceno superior en el segmento norte de la Cordillera Occidental e implicaciones tectónicas en el modelo geológico del noroccidente colombiano. Boletín Ciencias de La Tierra, 31: 5-22.

Rodríguez, G., Zapata, G., y Gómez, J.F. 2010. Geología de la Plancha 114 Dabeiba. Servicio Geológico Colombiano, Medellín, 205p.

Rodríguez, G., Zapata, G., y Gómez, J.F. 2014. Geología de la Plancha 114 Dabeiba. Revisión y actualización. Servicio Geológico Colombiano, Medellín, 207p.

Siivola, J., and Schmid, R. 2007. A systematic nomenclature for metamorphic rocks. 12. List of mineral abbreviations. Recommendations by the IUGS Subcommission on the Systematics of Metamorphic Rocks: Web version 01.02.07. SCMR website http:// www.bgs.ac.uk/SCMR.

Slama, J., Kosler, J., Condon, D.J., Crowley, J.L., Gerdes, A., Hanchar, J.M., Horstwood, M.S.A., Morris, G.A., Nasdala, L., Norberg, N., Schaltegger, U., Schoene, B., Tubrett, M.N., and Whitehouse, M.J. 2008. Plesovice zircon - a new natural reference material for $\mathrm{U}-\mathrm{Pb}$ and Hf isotopic microanalysis. Chemical Geology. 249: 1-35.

Solari,L.A., Gómez-Tuena,A.,Bernal,J.P.,Pérez-Arvizu, and O. Tanner, M. 2010. U-Pb zircon geochronology by an integrated LA-ICPMS microanalytical workstation: achievements in precision and accuracy. Geostandards and Geoanalytical Research, 34(1): 5-18.

Streckeisen, A., 1979. A classification and nomenclature of volcanic rocks, lamprophyres and melilitic rocks: Recommendations and suggestion of the IUGS on the Systematic of igneous Rocks. Geology, 7: 331-335.

Vinasco, C.J., Cordani, U.G., González, H., Weber, M., and Peláez, C. 2006. Geochronological, isotopic and geochemical data from Permo Triassic granitic gneisses and granitoids of the Colombian Central Andes. Journal of South American Earth Sciences, 21(4): 355-371.

Wiedenbeck, M., Alle, P., Corfu, F., Griffin, W.L., Meier, M., Oberli, F., von Quadt, A., Roddick, J.C., Spiegel, W. 1995. Three natural zircon standards for U-Th- Pb, Lu-Hf, trace-element and REE analyses. Geostandards Newsletter 19: 1-23.

Zapata, G. y Rodríguez, G. 2012. Basalto de El Botón, arco volcánico mioceno de afinidad shoshonítica al norte de la Cordillera Occidental de Colombia. Boletín de Ciencias de la Tierra, 30:77-91.

Trabajo recibido: mayo 21 de 2014

Trabajo aceptado: agosto 10 de 2015 